\title{
RA?EGA
}

O ESPACYO GEOGRÁFICO EM ANÁLISE

\section{CONTRIBUIÇÃO À COMPREENSÃO DO CAMPO TÉRMICO DA REGIONAL PRAIA DO CANTO, EM VITÓRIA (ES) PELA METODOLOGIA DE TRANSECTOS ${ }^{1}$}

\section{CONTRIBUTION TO THE UNDERSTANDING OF THE REGIONAL FIELD HEAT IN REGIONAL PRAIA DO CANTO, IN VITÓRIA (ES) BY TRANSECTS METHODOLOGY}

\author{
Wesley de Souza Campos Correa \\ Universidade Federal do Espírito Santo \\ Vitória, ES, Brasil \\ e-mail: wesley.campos.correa@gmail.com \\ Cláudia Câmara do Vale \\ Universidade Federal do Espírito Santo \\ Vitória, ES, Brasil \\ e-mail: camaravale@gmail.com
}

Recebido em: 21/06/2016

Aceito em: 19/04/2016

\section{Resumo}

As diferenças de uso e ocupação da terra nas cidades geram um clima próprio, ou seja, um clima urbano, que é resultante dos fatores urbanos, do clima regional e do meio físico local. Diante desse contexto, o presente artigo tem por objetivo estudar o comportamento térmico da Regional V - Praia do Canto, no município de Vitória (ES), por meio da técnica do transecto móvel (Fialho, 2009), em duas estações no ano de 2013, um realizado no verão (fevereiro), outro realizado no inverno (junho). Os resultados mostram que, tanto no verão, quanto no inverno, as áreas mais aquecidas ficaram bem definidas, estas áreas são correspondentes aos núcleos térmicos. As maiores influências do tecido urbano na temperatura do ar foram verificadas sob atuação da Alta Subtropical do Atlântico Sul (ASAS). Foram observadas nos dois períodos (verão/inverno), elevadas amplitudes térmicas. Às 09 horas, são registradas as maiores amplitudes térmicas nos dois períodos analisados. Às 15 horas, no verão e no inverno, verificou-se que a porção centro-leste da área em estudo apresenta até $3^{\circ} \mathrm{C}$ a menos nos períodos vespertinos em relação aos pontos localizados na porção norte e sul da área. A análise confirmou que as mudanças de uso e cobertura da terra, associadas às características do relevo local, bem como à dinâmica atmosférica, influenciam diretamente as variáveis meteorológicas, neste caso a temperatura do ar.

$1 \quad$ Os autores agradecem a Fundação de Apoio a Pesquisa do Estado do Espírito Santo (FAPES), pela concessão da bolsa de pesquisa que viabilizou a realização desse projeto de pesquisa. 
Palavras chaves: Alta Subtropical do Atlântico Sul (ASAS), clima urbano, temperatura do ar.

\section{Abstract}

The diferences in the land use and land cover in cities generate a unique climate, i.e, an urban climate, which is a result of several factors, as a regional weather and physical characteristics. In this context, this article aims to study the thermal behavior of the Regional V - Praia do Canto in Vitória, Espírito Santo province, using the mobile transect methodology (Fialho, 2009), in two distinct periods in 2013, one in the Summer (February) and other in the Winter (June). The results show that both in summer and winter, the heat points remained well defined. The major influences of the urban edification in air temperature were observed during the occurence of the South Atlantic Subtropical High (ASAS). They were observed in both periods - Summer and Winter -, high temperature range. At 9 a.m., the highest temperature gradients in both periods analyzed were recorded. At 3 p.m. in the Summer and Winter, it was found that the east-central portion of the area under study presents an increasement up to $3^{\circ} \mathrm{C}$ except in the evening periods for the points located in the northern and southern portion of the study area. The analysis confirmed that the changes in land use and land cover, associated to the local physical characteristics, as well as atmospheric dynamics influenciates directly the variables of the weather, in this case the air temperature.

Key words: South Atlantic Subtropical High (ASAS), urban climate, air temperature.

\section{INTRODUÇÃO}

As transformações sobre a superfície urbana provocam alterações no balanço de energia e no balanço hidrológico, influenciando diretamente a temperatura do ar, a umidade relativa do ar, a velocidade e direção do vento, com isso, as cidades geram clima próprio, ou seja, um clima urbano, que é resultante dos fatores urbanos, do clima regional e das características físicas locais (ANDRADE, 2005, LANDSBERG, 2006).

Entendendo que as cidades causam mudanças no clima local produzindo um clima próprio, vários estudos de natureza teórica, ou observacional, foram realizados no âmbito internacional (JAREGUI, 1973, OKE, 1974, LOWRY, 1977; LEE, 1990; GÓMEZ e GARCIA, 1995; ALCOFORADO, 1999; ICHIONOSE et al., 1999, ANDRADE, 2005; GARTLAND, 2010) e nacional (MONTEIRO, 1976; LOMBARDO, 1985; MENDONÇA, 1995; AMORIM, 2000; SANT'ANNA NETO, 2002; BRANDÃO, 2003; MONTEIRO, 2003; FIALHO, 2009; ASSIS, 2010). Entretanto, Assis (2005) ressalta que, 
enquanto as pesquisas na Europa e na América do Norte aprofundaram-se na modelização física e numérica, boa parte dos estudos em áreas tropicais possuem enfoque descritivo das ilhas de calor e da qualidade do ar, com pouca atenção ao balanço energético, modelagem e desenvolvimento de aplicações para o planejamento urbano.

Diante do exposto, este artigo tem como objetivo estudar o comportamento térmico da Regional V - Praia do Canto no município de Vitória (ES), a qual é composta por 9 bairros e abrange uma área de $5.315 .956 \mathrm{~m}^{2}$, por meio da técnica do transecto móvel (FIALHO, 2009), em duas estações distintas no ano de 2013, uma no verão (fevereiro), que representa o período chuvoso e outra no inverno (julho), que representa o período menos chuvoso da área em estudo.

\section{CARACTERIZAÇÃO DA ÁREA EM ESTUDO}

O município de Vitória, capital do estado do Espírito Santo, possuí uma área de 93,38 km² (IBGE, 2002) e densidade demográfica de aproximadamente $3.527 \mathrm{hab} / \mathrm{km}^{2}$ com cerca de 355 mil habitantes (IBGE,2015) com intensa verticalização de seu espaço urbano (COSTA, 1992).

A organização político-administrativa do município é regulamentada pela Lei 8.611/2013. Tal lei permitiu a organização da cidade em 80 bairros e 9 regionais, a saber elas: I) Regional Centro; II) Regional Santo Antônio; III) Regional Jucutuquara; IV) Regional Maruípe; V) Regional Praia do Canto; VI) Regional Goiabeiras; VII) Regional São Pedro; VIII) Jardim Camburi; IX) Jardim da Penha (Figura 01). 


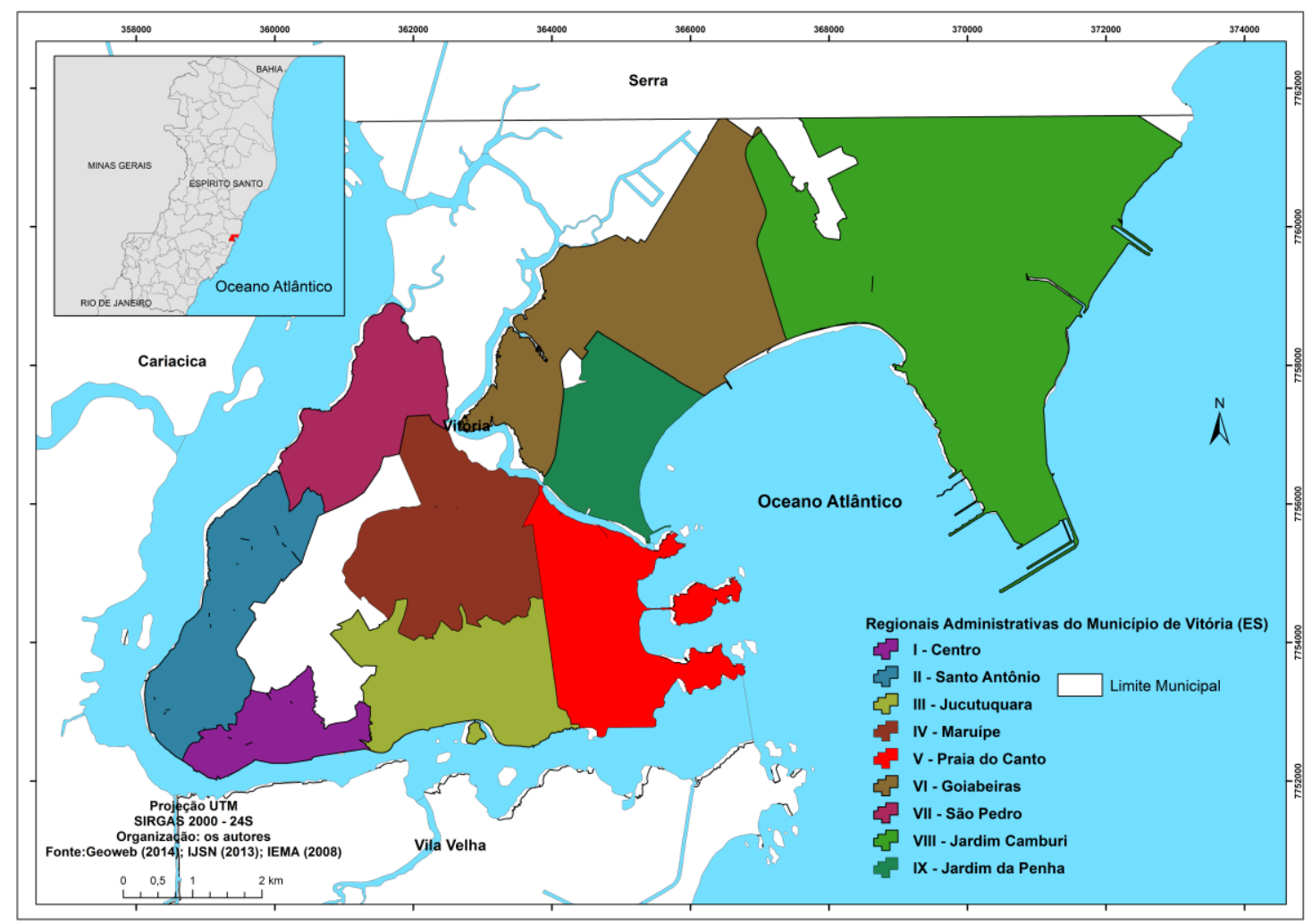

Figura 01: Localização da área em estudo e Regionais Administrativas

A Regional V - Praia do Canto (RPC) possui a melhor infraestrutura do município, abrigando ilhas, praças, praias, intensa atividade de comércio e serviços, além de residências para a classe média alta (PMV, 2013). Dos nove bairros que esta regional abrange apenas as Ilhas do Boi e do Frade possuem as formas de uso e ocupação e comportamento climático diferentes, por isso estas áreas não estão inclusas neste estudo.

Em relação à climatologia do município, para o período de 1978 a 2007, Vitória apresentou totais pluviométricos anuais de $1.320 \mathrm{~mm}$, sendo os meses mais chuvosos: novembro, com 199,8mm, dezembro, com 219,9mm e janeiro, com $153,7 \mathrm{~mm}$, com temperaturas médias variando de $24,5^{\circ} \mathrm{C}$ a $27,7^{\circ} \mathrm{C}$ e umidade relativa do ar em torno de $75 \%$. A estação menos chuvosa ocorre entre os meses de maio a setembro, com temperatura média alternando entre $22^{\circ} \mathrm{C}$ e $23^{\circ} \mathrm{C}$, com baixos índices pluviométricos, que variam entre $54 \mathrm{~mm}$ e $77 \mathrm{~mm}$ (CORREA, 2011). Os principais fenômenos meteorológicos, em escala sinótica, que influenciam a variabilidade do tempo no município de Vitória, são 
CONTRIBUIÇÃO À COMPREENSÃO DO CAMPO TÉRMICO DA REGIONAL PRAIA DO CANTO, EM VITÓRIA (ES) PELA METODOLOGIA DE TRANSECTOS

a Zona de Convergência do Atlântico Sul (ZCAS), as Frentes Frias (FF) e o Anticiclone Subtropical do Atlântico Sul (ASAS) (REBOITA et al., 2010). Além desses fenômenos, a brisa marítima (efeitos de maritimidade), atua influenciando as características do tempo do município, que é banhando pelo oceano Atlântico.

\section{MATERIAIS E MÉTODOS}

\subsection{Aporte Teórico e metodológico}

Esta pesquisa foi realizada segundo proposta de Monteiro (1976), para o estudo de clima das cidades, o Sistema Clima Urbano (SCU), abordando apenas o Subsistema Termodinâmico. Destaca-se, que para atingir os objetivos ora propostos, fora necessário buscar subsídios nas proposições estabelecidas por Andrade (2005), Monteiro (1976; 1990), Brandão (1996; 2003), Sant'Anna Neto e Amorim (2009), Fialho (2009) e Assis (2010), Gartland (2010). Outrossim, neste artigo será abordado o conceito núcleo de térmico que, segundo Assis (2010), pode ser compreendido como, localidades com os maiores valores térmicos dentro de uma mesma realidade urbana.

\subsection{Trabalho em campo e Transectos Móveis}

$\mathrm{Na}$ busca por identificar a interferência dos diferentes tipos de uso e ocupação da terra sobre o campo térmico da Regional da Praia do Canto (RPC), foi monitorada a temperatura do ar para os horários de 9, 15 e 20 horas com o uso de transectos móveis. A escolha pelos horários de observação segue metodologia proposta por Fialho (2009), Sant'Anna Neto e Amorim (2009), pois, os dois primeiros horários são os de maior insolação e já no terceiro horário, a temperatura do ar não experimenta alterações rápidas e, com o pôr do Sol, os materiais da superfície liberam o calor conservado.

Para analisar a temperatura do ar, foram selecionados dois períodos durante o ano de 2013 que representassem as características climáticas existentes no município, no caso, a estação mais chuvosa, de outubro a março e a menos chuvosa, de abril a setembro (CORREA, 2011). Fialho (2009) e Assis (2010), destacam que não há uma padronização para o quantitativo de 
dias das coletas em campo, uma vez que, estas dependem de vários fatores, como por exemplo, a disponibilidade das pessoas que auxiliaram na pesquisa, entretanto, há necessidade de que os dias escolhidos, sejam representados, dentro das características climáticas da região. Fialho (2009) na sua tese de doutorado para o estudo de clima urbano em Viçosa (MG), dividiu a análise das variáveis atmosféricas em campo em dois períodos, chuvoso e menos chuvoso, compostos, por 3 (três) e 2 (dois) dias respectivamente.

Seguindo padrão de amostragem realizado por Fialho (2009), neste artigo, a análise das variáveis atmosféricas, ocorrem da seguinte forma: 0 primeiro período de coleta de dados em campo, ocorreu nos dias 19, 20 e 21 de fevereiro, que representa a estação chuvosa e também o verão no hemisfério sul. Enquanto o segundo período, o menos chuvoso, sucedeu no inverno, nos dias 27 e 28 de junho, pois, é quando os principais componentes atmosféricos que influenciam os efeitos de ilha de calor, como inversão térmica, estagnação atmosférica e altas concentrações de poluentes, são mais frequentes (LOMBARDO, 1985).

A área em estudo apresenta 29 pontos amostrais dividido em 5 trajetos de transectos e foram realizados a pé. Todos os transectos partiram de oeste que se caracteriza como como área menos verticalizada, e possuem presença de maciços e colinas costeiras e também estão próximos à Avenida Leitão da Silva, em sentido para leste, que se distinguem como áreas mais verticalizadas e próximas ao litoral (Figura 02). Entre as vantagens da realização deste procedimento por meio da técnica dos transecto móvel e a pé, segundo Fialho (2009), ressaltar-se: abrange melhor a heterogeneidade do meio urbano, aumenta o número de pontos de coleta dentro da área de estudo, bem como, proporciona maior agilidade no processo de monitoramento.

A escolha dos pontos amostrais fora pautada nas proposições apresentadas por Assis (2010) e Monteiro (1990c), considerando a estrutura e dinâmica urbana da regional (sítio urbano), além, da quantidade de equipamentos e mão de obra disponível para realização do estudo. Também, destaca-se, que para escolha dos pontos utilizou-se como referência o mapa de uso e gestão do solo urbano de Vitória (ES) (PMV, 2013), o que permitiu um 
conhecimento prévio da área em estudo. Abaixo, são expostos na Figura 02 e

Tabela 01, os transectos com os pontos de coleta e a descrição de cada ponto, respectivamente.

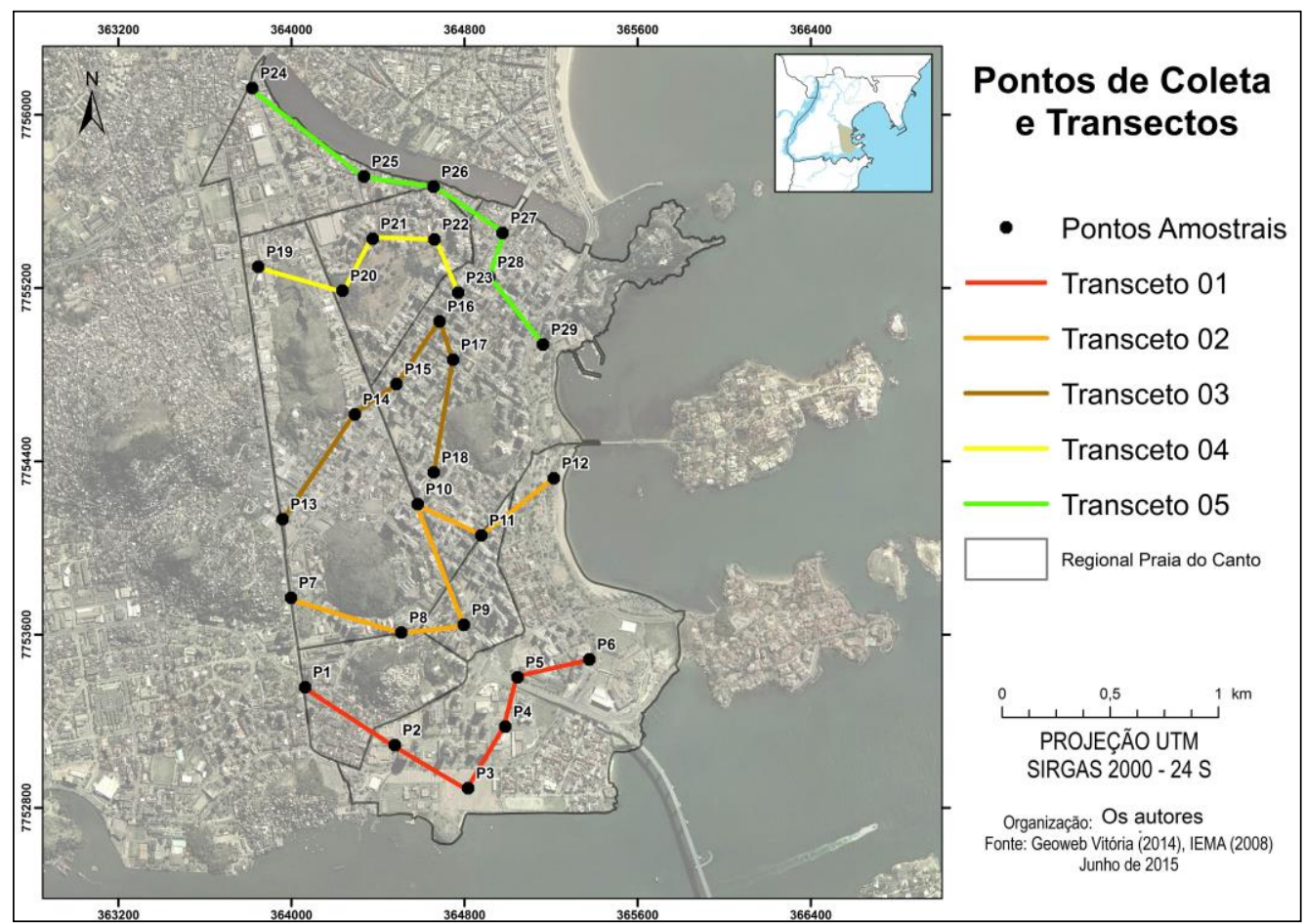

Figura 02: Pontos de Coleta e Transectos.

Tabela 01: Descrição de cada ponto

Ponto - Localização

$1^{\circ}$ Transecto, Bifurcação a Avenida Leitão da Silva com a Rua Arnold Neves.

$2 \quad \begin{aligned} & 1^{\circ} \text { Transecto, Rua Treze, em } \\ & \text { frente a unidade de saúde "Lucilo }\end{aligned}$ frente a unidade de saúde "Lucilo
Borges Sant'Anna".

\begin{tabular}{l|l}
\hline 3 & $1^{\circ}$ Transecto, Praça do Papa
\end{tabular}

4

$1^{\circ}$ Transecto, Praça em frente ao palácio de justiça. de Bombeiros do Espírito Santo e

Terceira Ponte.

$61^{\circ} \quad$ Transecto, Assembleia Legislativa do Espirito Santo

apresentam fachadas de vidro.

\section{Caracterização}

Local com continuo fluxo de veículos, Ruas asfaltadas; as construções possuem fachadas de alvenaria e também de vidro; há árvores e vegetação herbáceas no canteiro central e árvores isoladas nas laterais.

fluxo de veículo, a rua é asfaltada; há arvores nos canteiros laterais da rua, edominantemente de vidro, com algumas exceções de alvenaria

Pouca vegetação, margeado pelo litoral, o calçamento da praça é de blocos em frente há prédios com fachadas totalmente de vidro e na via há fluxo

$2^{\circ}$ Transecto, Avenida Leitão da Canteiro central entre a Av. Leitão da Silva e a Rua Misael Pedreira da Silva Silva com a Rua Misael Pedreira há continuo fluxo de veículos, os edifícios possuem padrão vertical e da Silva.

$8 \quad 2^{\circ}$ Transecto, Av. Cesar Helal, horizontal de uso comercial, Atrás da avenida há um maciço (morro do

al, Av. asfaltada com contínuo fluxo de veículos; em frente existe um maciço com bastante vegetação, as edificações possuem o padrão vertical com dois ou mais pavimentos de uso comercial ou residencial.

$9 \quad 2^{\circ}$ Transecto, Av. Nossa Senhora Praça com várias árvores e gramada; há vários prédios ao redor com da Penha / Praça Cristóvão fachadas de alvenaria e vidro; Av. ao redor possui um fluxo contínuo de Jaques (Cauê). veículo.

$102^{\circ}$ Transecto, Av. Nossa Senhora Av. asfaltada com fluxo intenso de veículos; as construções são verticais e da Penha / Próximo a Caixa fazem sombreamento na Av. e as fachadas dos prédios variam entre vidros $\mathrm{e}$ Econômica e Shopping. $\quad$ cimento. A circulação de pessoas é constante;

$112^{\circ}$ Transecto ponto 5 - Av. Canteiro central da Av. Desembargador Santos Neves que é asfaltada Desembargador Santos Neves. existem bastantes arvores no canteiro central e nas laterais; as construções são verticais e fazem sombreamento na Av. e as fachadas dos prédios variam entre vidros e cimento

$122^{\circ} \quad$ Transecto, Praça na Av. Praça é margeada pelo litoral (praia); há arvores, porém, bastante espaçadas Saturnino de Brito. $\quad$ O calçamento é de blocos; de frente para Praça na Av., há fluxo intenso de veiculo.

R. Ra'e Ga - Curitiba, v. 38, p.50 - 81, Dez/2016 
Ponto - Localização

Caracterização

13 3 $3^{\circ}$ Transecto, Canteiro central da Há um intenso fluxo de veículos; as construções são de caráter comercial Avenida Leitão da Silva, em frente com algumas casas, há poucos prédios com dois pavimentos ou mais à maternidade Granmater. $\quad$ material de construção predominante é alvenaria e as fachadas de cimento exceto, na Granmater e Todeschini que possuem fachadas predominantes de vidro; há arvores próximo ao local; atrás fica o morro do Gurigica;

$143^{\circ}$ Transecto, Canteiro central da|Av. com intenso fluxo de veículos, uma das principais av. da cidade, os Av. Reta da Penha. $\quad$ prédios são de uso comercial com dois ou mais pavimentos e os materiais de construção são de alvenaria e há fachadas de vidro e cimento, não há árvores. Canteiro central com gramas e florido.

$153^{\circ}$ Transecto, Esquina em Frente Construções Modernas, padrão vertical superior há 10 pavimentos com uso à Casa de Carne Frisa, que varia para moradia e escritórios de empresas; há algumas casas próximo cruzamento da Av. Rio Branco ao ponto de coleta de dados. A pavimentação da via é de asfalto e há com a Rua João Silva Abreu.

$163^{\circ}$ Transecto, Bifurcação da Av. O Padrão de construção dos edifícios é vertical com dois ou mais pavimentos Castelo Branco - Rua Chapot os materiais utilizados nas fachadas dos prédios variam entre o cimento e

Presvot. Condomínio de Compras/vidro; Cobertura da via é asfáltica e há muitas árvores nas calçadas laterais e Solar da paria.

$173^{\circ}$ Transecto, Rua Aleixo Neto, Há arvores nos canteiros do lado esquerdo e direito da rua; as edificações Rotatória no centro da Rua Aleixo são de padrão vertical com dois ou mais pavimentos de uso residencial Netto

18 30 Transecto, Rua Eugênio Neves.
predominante, as fachadas variam entre de cimento e vidros; fluxo constante de veículos. rua asfaltada Monteiro com a Av. Leitão da
Silva.

20 4 $4^{\circ}$ Transecto, Av. Nossa Senhora Área com pouca vegetação, na frente Av. Nossa Senhora da Penha há um da Penha, em frente a Petrobrás. maciço; O fluxo de veículos na avenida é intenso; A maioria dos imóveis são para comércio, negócios. As construções possuem fachada de vidro, cerâmica, alvenaria.

$214^{\circ}$ Transecto, Rua José Luiz Contínuo fluxo de veículos; há árvores no local; O calçamento da rua é de Gabera - Barro Vermelho, bloco; Área de uso comercial e residencial. As fachadas dos prédios são de próximo ao Edifício Espácio vidro e de alvenaria.

Albert.

22 年 Transecto, Rua Vila Lobos, em Á frente à loja impacto

$4^{\circ}$ Transecto, Rua Celso Calmon com a Avenida Rio Branco.

$245^{\circ}$ Transecto, Bifurcação da Av.

vavimentadas com asfalto, com intenso fluxo de veículos, Próximo

Reta da Penha com a Av Serafim ao canal "de vitória"; não há arvores na proximidade; há predominância das Derenze. $\quad$ edificações horizontais com algumas em verticais.

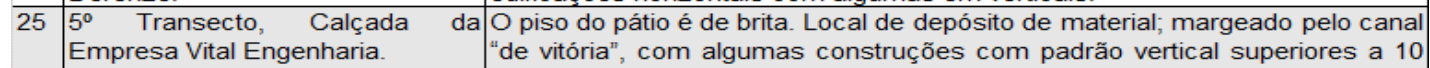

$265^{\circ}$ Transecto, Rua Grécia. pavimentos Santo.

$275^{\circ}$ Transecto, Em frente a ponte Airton Senna na Av. Rio Branco.

28 5 $5^{\circ}$ Transecto, Rua Afonso Claudio, próximo ao Maison Classic.

295 Transecto, Praça CLUB. afloramento rochoso; Rua tem um fluxo pequeno, porém, constante de veículos; O local é aberto é o solo é descoberto; de frente para o ponto é o canal de Vitória.

(uxo intenso e constante de veículos; Avenida Pavimenta com asfalto; vários próximos ao ponto, cuja fachada varia entra alvenaria e vidros, Gramas sobre o canteiro central

Em ambos os lados da rua há prédios com 10 ou mais pavimentos de uso comercial e residencial; A rua é asfaltada. Há arvores nas laterais.

dos Calçamento da Praça é feito de blocos O local é margeado pelo litorat possui arvores; Em frente à praça há Avenida Saturnino de Brito, com fluxo
intenso de veículos e vários prédios com a fachada de vidros.

Outro procedimento adotado para escolha dos pontos foi dividir a Regional Praia do Canto, que possuí de $5.315 .956 \mathrm{~m}^{2}$ de extensão por 5 (cinco), quantidade de equipamento disponível, o que resultou em uma distância aproximada de pouco mais de 1000 metros entre os pontos que iniciavam os transectos, entretanto, para P7 e P13, esse procedimento não foi estritamente adotado, pois, houve necessidade de desviar dos maciços (Figura 2). Para os pontos que compunham cada transecto, no sentido de oeste para 
CONTRIBUIÇÃO À COMPREENSÃO DO CAMPO TÉRMICO DA REGIONAL PRAIA DO CANTO, EM VITÓRIA (ES) PELA METODOLOGIA DE TRANSECTOS

leste, buscou-se dividir em partes iguais a distância entre as bordas da Regional Praia do Canto, o que resultou em 6 pontos para cada transecto com distância aproximada de 500 metros entre os pontos. Excepcionalmente, o transecto 4 possui 5 pontos de amostragem.

Cada transecto foi feito a pé, levando 1h15min para concluí-los. O intervalo de coleta entre os pontos foram de 15 (quinze) minutos, obedecendo o intervalo de mensuração das variáveis atmosféricas da estação meteorológica do Instituto Nacional de Meteorologia (INMET) do município de Vitória, que fornece os dados a cada 15 minutos, condição que permitiu a correção da defasagem do tempo, conforme ainda será explicada nesta metodologia.

\subsection{Equipamentos Utilizados em Campo: Abrigos Meteorológicos e Aferição dos Termo-Higrômetro Datalogger}

A mensuração da temperatura do ar fora realizada com Termohigrômetro digital (datalogger IP-747 $\mathrm{RH}$ Temperatura e Umidade USB) fabricado pela empresa IMPAC. O abrigo meteorológico móvel utilizado foi um tubo de PVC com diâmetro de $100 \mathrm{~cm}$ x $50 \mathrm{~cm}$, coberto por papel alumínio, com aproximadamente 2 metros de altura, conforme proposto por Fialho (2009). A porção superior do cano de PVC possuí revestimento de papel alumínio para refletir a radiação incidente do Sol sobre o termohigrômetro (Figura 03).

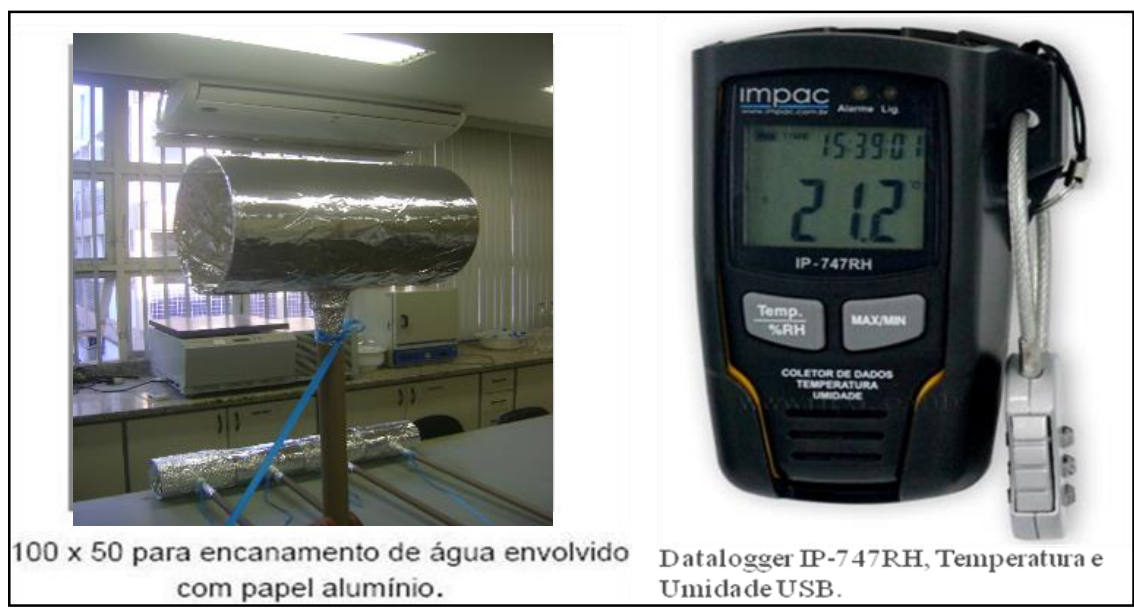

Figura 03: Tubo de PVC $100 \mathrm{~cm} \times 50 \mathrm{~cm}$ para encanamento de água envolvido com papel alumínio e Datalogger IP-747 RH, Temperatura e Umidade USB. 
CONTRIBUIÇÃO À COMPREENSÃO DO CAMPO TÉRMICO DA REGIONAL PRAIA DO CANTO, EM VITÓRIA (ES) PELA METODOLOGIA DE TRANSECTOS

\subsection{Correção da defasagem do tempo}

Os dados de temperatura do ar, por meio do transecto móvel, apresentam defasagem de tempo. Em função disso os valores passam por uma correção temporal, visando calibrar os dados levantados, conforme metodologia proposta por Fialho (2009) (Tabela 02).

\begin{tabular}{c|c|c|c|c|c} 
Ponto & Hora & Temp & Temp.1 & Dif & $\begin{array}{c}\text { Temp. } \\
\text { Corrigida }\end{array}$ \\
\hline 1 & $09: 00$ & 20 & 21 & 0 & 20 \\
\hline 2 & $09: 10$ & 21 & 21,3 & 0,3 & 20,7 \\
\hline 3 & $09: 20$ & 21,2 & 21,6 & 0,6 & 20,6 \\
\hline 4 & $09: 30$ & 21,8 & 22 & 1 & 20,8 \\
\hline 5 & $09: 40$ & 21,6 & 22,3 & 1,3 & 20,3 \\
\hline 6 & $09: 50$ & 22 & 22,6 & 1,6 & 20,4 \\
\hline 7 & $10: 00$ & 21,8 & 23 & 2 & 19,8 \\
\hline
\end{tabular}

Tabela 02: Exemplo de correção da temperatura.

Temp. Temperatura observada em Campo. Temp.1 Temperatura da estação Automática.

Dif. Diferença ao longo do tempo de 01:00 hora. Temp. Corrigida: Subtrai a Dif. dá Temp. para o caso das medidas diurnas, quando registra uma tendência de aumento de temperatura e inverso para a noite, quando verifica-se um resfriamento.

Fonte: Adaptado de Fialho (2009).

Para aferir os termos-higrômetros, os equipamentos foram arrumados em uma bancada de granito a aproximadamente $80 \mathrm{~cm}$ do chão, com portas e janelas fechadas e lâmpadas apagadas no Laboratório de Geografia Física da Universidade Federal do Espírito Santo (UFES).

A coleta das amostras ocorreu no período de 11:45h ás 15:15h, no dia 06 de fevereiro de 2013. Foram coletadas manualmente 5 amostras de temperatura do ar nos cincos aparelhos usados nos primeiros 30 minutos e observou-se que nenhum aparelho apresentou desvio em relação a mensuração. Após este primeiro teste, o aparelho 1 foi escolhido aleatoriamente para ser comparado com o desempenho dos demais. Em seguida a este procedimento, foram programados para realizarem a coleta automaticamente a cada 10 segundos. Foram feitas 1302 observação no total. $\mathrm{O}$ desvio padrão para os dados de temperatura foi de $0,2^{\circ} \mathrm{C}$, para todos os 
CONTRIBUIÇÃO À COMPREENSÃO DO CAMPO TÉRMICO DA REGIONAL PRAIA DO CANTO, EM VITÓRIA (ES) PELA METODOLOGIA DE TRANSECTOS

aparelhos. Tais discrepâncias nos dados observados estão dentro dos limites estabelecidos pelo fabricante que é de $0,1^{\circ} \mathrm{C}$ e precisão de $\pm 1^{\circ} \mathrm{C}$ e $\pm 2^{\circ} \mathrm{C}$, logo, o resultado encontrado na calibração está dentro do desvio esperado.

\subsection{Acompanhamento da Dinâmica do Tempo}

O acompanhamento da dinâmica atmosférica foi realizado a partir de cartas sinóticas de superfície e imagens de satélite, ambas às 12 e 18 horas Zulu, junto ao Centro de Previsão de Tempo e Estudos Climáticos (CPTEC), da Diretoria de Hidrografia e Navegação (DHN) / Serviço Meteorológico Marinho (CMM) e do Instituto Capixaba de Pesquisa, Assistência Técnica e Extensão Rural (INCAPER). Às informações das variáveis meteorológicas da Estação Meteorológica localizada na UFES, foram fornecidas pelo INMET (2013).

\subsection{Base cartográfica e confecção dos mapas}

As bases cartográficas utilizadas no presente estudo foram: Limite Municipal, Área Urbana, Bairros e Ortofotomosaico Digital 1/5.000 ambas cedidas pela Coordenação de Geoprocessamento do Instituto Jones dos Santos Neves - CGEO/IJSN (2011). Os dados foram trabalhados no software ArcGIS 10.1 e ajustados, quando necessário, no sistema de projeção UTM, Datum SIRGAS 2000, Zona 24 Sul. A representação cartográfica fora realizada com o objetivo de representar o comportamento diário da temperatura.

No intuito de compreender as influências do uso e ocupação na temperatura do ar na Regional Praia do Canto, foi confeccionado o mapa de uso e ocupação da terra para área em estudo. Para tal feito, foi utilizada a base cartográfica Gestão e controle urbano, cedido pela Prefeitura Municipal de Vitória (2013) por meio da Coordenação de Geoprocessamento da Secretaria Municipal da Fazenda e Subsecretaria de Tecnologia e Informação.

\subsection{Interpolação dos dados}

A utilização da interpolação permite o conhecimento do comportamento de determinadas variáveis em setores onde não existem amostras (CASTRO e LOPES, 2011). Neste estudo foram testados seis métodos de interpolação: o Inverso das distâncias ao quadrado (IDW), Krigagem Simples (KS), Krigagem 
Ordinária (OK), Radial Basic Functions (RBF), Polinomial Local (LPI), Polinomial Global (GPI), ambos com o auxílio do software ArcGis 10.1. Para validação da interpolação, seguiu-se metodologia proposta por Li e Heap (2011), Wu e Li (2013), que se constituí em uma comparação simples entre os valores brutos obtidos por meio de um critério de parcimônia, a saber: erro médio $(\mathrm{ME})$, desvio padrão $(\sigma)$, erro médio quadrático (MSE), coeficiente de correlação (r), raiz quadrada do erro médio quadrático (RMSE) e Índice de Concordância (d) (WILLMOTT et al., 1985).

Após os cálculos (Tabela 03) verificou-se que todos os métodos apresentaram medidas satisfatórias, ou seja, não observou uma diferença significativa, mesmo assim, o GPI, LPI e SK apresentam ME abaixo do esperado. Entretanto Li e Heap (2011), Wu e Li (2013), destacam em seus estudos que os melhores resultados são obtidos por meio da Krigagem, porém, Alves et al., (2012), realçam que um método de interpolação espacial para um elemento meteorológico pode não ser satisfatório para outros elementos e que deve-se escolher o método de interpolação de acordo com o objeto de estudo, área de pesquisa, escala, coleta de dados.

Nos testes com o IDW os valores reais das amostras foram mantidos e nos mapas não houveram inferências na representatividade dos valores de temperatura do ar. Com o RBF e a Krigagem, os valores máximos e mínimos foram subtraídos pelo modelo nos mapas gerados. Os métodos GPI e o LPI geraram mapas com problemas de interpolação, com representação espacial totalmente diferente dos demais, bem como, valores irreais.

Mediante justificativas apresentadas, optou-se em utilizar o método IDW, pois, este permitiu-nos modelar geograficamente o comportamento térmico, tornando-se possível definir padrões térmicos diferenciados, além de manter os valores reais dos dados observados em campo. 
CORREA, W. S. C. ; VALE, C. C.

CONTRIBUIÇÃO À COMPREENSÃO DO CAMPO TÉRMICO DA REGIONAL PRAIA DO CANTO, EM VITÓRIA (ES) PELA METODOLOGIA DE TRANSECTOS

Tabela 03: Comparação entre os modelos de Interpolação

\begin{tabular}{|c|c|c|c|c|c|c|c|}
\hline $\begin{array}{c}\text { Modelo de } \\
\text { Interpolação }\end{array}$ & $r$ & ME & RMSE & RMSE UB & $\sigma_{\text {pre }}$ & $\sigma_{\text {obs }}$ & $d$ \\
\hline IDW & 0,54 & 0,02 & 0,34 & 0,36 & 0,20 & 0,41 & 1,00 \\
\hline RBF & 0,58 & 0,00 & 0,33 & 0,33 & 0,27 & 0,41 & 1,00 \\
\hline GPI & 0,45 & $-0,05$ & 0,37 & 0,42 & 0,15 & 0,41 & 1,00 \\
\hline LPI & 0,63 & $-0,01$ & 0,32 & 0,32 & 0,21 & 0,41 & 1,00 \\
\hline SK & 0,52 & $-29,03$ & 0,35 & 0,35 & 0,26 & 0,41 & 1,00 \\
\hline OK & 0,49 & 0,02 & 0,37 & 0,38 & 0,33 & 0,41 & 1,00 \\
\hline
\end{tabular}

Fonte: Elaborada pelos autores.

\section{RESULTADOS E DISCUSSÃO}

\subsection{Uso e ocupação da terra na Regional Praia do Canto}

$\mathrm{Na}$ Figura 03 é apresentado as características do uso e ocupação da terra para Regional Praia do Canto por cada bairro que compõe a área em estudo. De modo geral, observa-se que a oeste estão concentradas áreas menos verticais e funcionalidade comercial, enquanto a leste, é observado o predomínio de áreas residencial multifamiliar de padrão vertical.

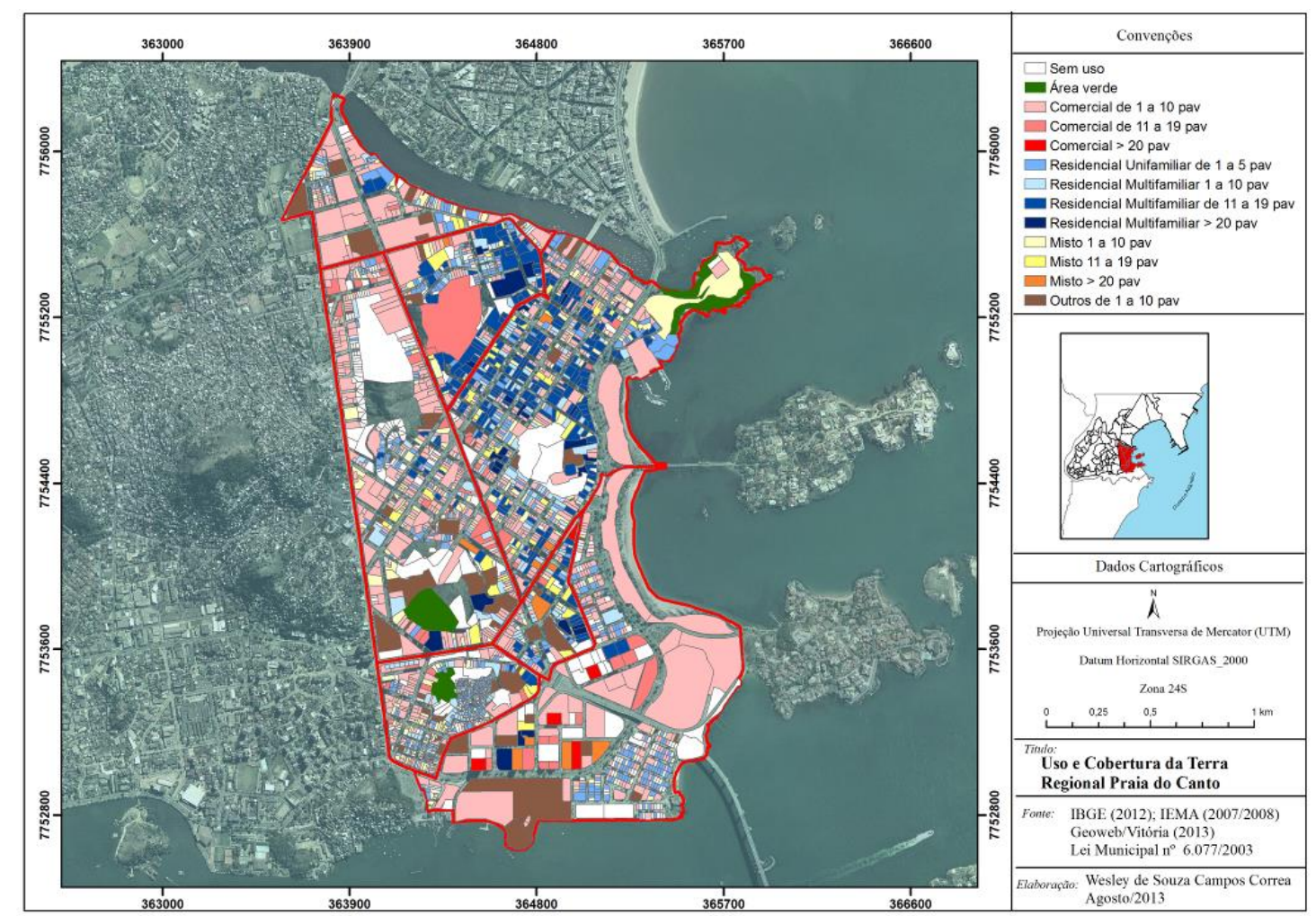

Figura 04: Principais Vias e Avenidas da Regional Praia do Canto.

Nos bairros Barro Vermelho e Praia do Canto há o predomínio de área residencial multifamiliar de 10 a 19 pavimentos e com mais de 20 pavimentos. 
CONTRIBUIÇÃO À COMPREENSÃO DO CAMPO TÉRMICO DA REGIONAL PRAIA DO CANTO, EM VITÓRIA (ES) PELA METODOLOGIA DE TRANSECTOS

Também há áreas de uso comercial com o predomino de 1 a 10 pavimentos e algumas áreas mistas. Em Santa Helena a maior parte da área é ocupada por residência multifamiliar com 11 a 19 pavimentos e também por área comercial com 1 a 10 pavimentos. Nos bairros Santa Lúcia e Santa Luíza (Figura 04) há o predomínio de área de uso comercial com 1 a 10 pavimentos e, algumas áreas de uso residencial multifamiliar. Na Enseada do Suá há grande concentração de área Comercial, com número de pavimento variando de 1 a mais de 20 pavimentos (Figura 04). Na Praia do Suá há maior concentração de área de uso residencial unifamiliar, com 1 a 5 pavimentos, áreas comerciais, construções de 1 a 10 pavimentos, neste bairro também há algumas áreas mistas.

\subsection{Condições Atmosféricas - Levantamento em campo I - entre os dias 19 a 21 de fevereiro de 2013 (verão)}

Com domínio da ASAS, verificou-se condições meteorológicas com céu claro e poucas nuvens. Neste período a pressão atmosférica manteve-se elevada, com 1009 hPa e temperatura do ar acima da média climatológica. Os ventos predominantes foram de norte, nordeste, noroeste e oeste-noroeste. A umidade relativa do ar manteve-se elevada, com média de 72,8\% (Figura 05).

Segundo o INCAPER (2013), nos dias 19/02 e 20/02, a umidade marítima (UM) e a circulação de brisa (CB) contribuíram para formação de nuvens durante a madrugada e início da manhã, porém, a nebulosidade logo se dissipou e houve o predomínio de temperaturas superiores a $30^{\circ} \mathrm{C}$ e vento predominante de direção norte. 


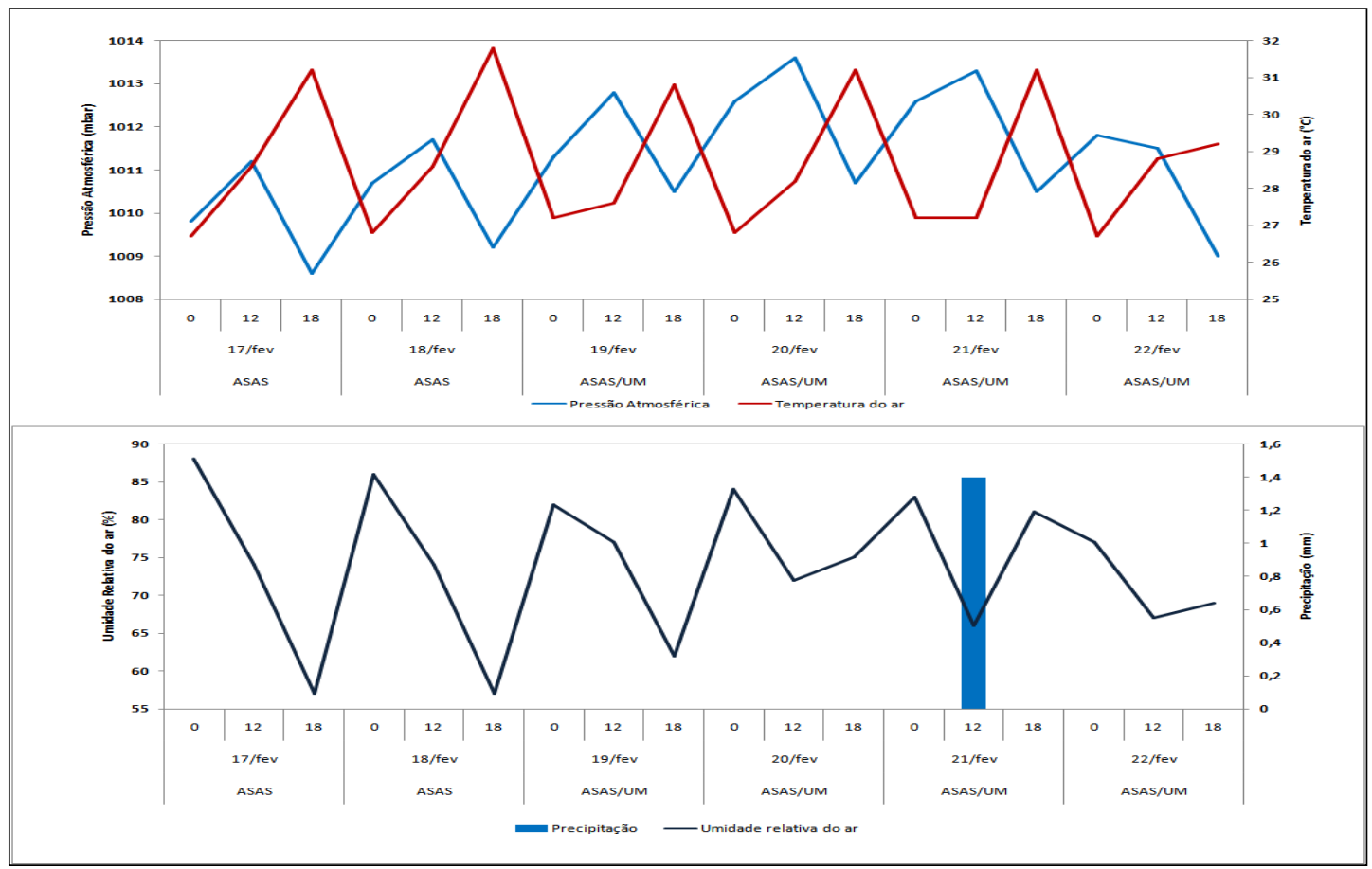

Figura 05: Evolução temporal da pressão atmosférica em superfície, da temperatura do ar, umidade relativa do ar e precipitação no período de 17/02 a 22/02/2013. Fonte de dados: INMET (2013).

No dia 21/02 a UM e a CB contribuíram para formação de várias nuvens durante a madrugada e em parte da manhã. Observou-se chuva fraca em alguns pontos do município por volta de 6 horas da manhã, com o acumulado diário de 1,4mm (INMET, 2013). Por volta das 9 horas à nebulosidade logo foi dissipada, com o predomínio de temperaturas altas, superior a $30^{\circ} \mathrm{C}$, e vento predominante de direção norte.

\subsection{Análise da temperatura do ar na RPC - Levantamento de Campo I}

O comportamento da temperatura do ar realizada por meio dos transectos móveis na RPC entre os dias 19 a 21/02/2013 às $9 \mathrm{~h}$, às $15 \mathrm{~h}$ e às 20h é mostrado na Figura 06. Ao analisar o campo térmico, é possível afirmar, que as temperaturas do ar estiveram entre $26,0^{\circ} \mathrm{C}$ a $34,5^{\circ} \mathrm{C}$ apresentando uma amplitude média de $8^{\circ} \mathrm{C} / \mathrm{dia}$. Os maiores valores de temperatura do ar foram registrados às $15 \mathrm{~h}$ nos três dias do levantamento. Porém, no dia 19/2 às 9h, 
foram observadas temperaturas elevadas nas porções norte (transecto 4 e 5) e sul (transecto 1 e 2) da área em estudo, semelhante às observadas às $15 \mathrm{~h}$.

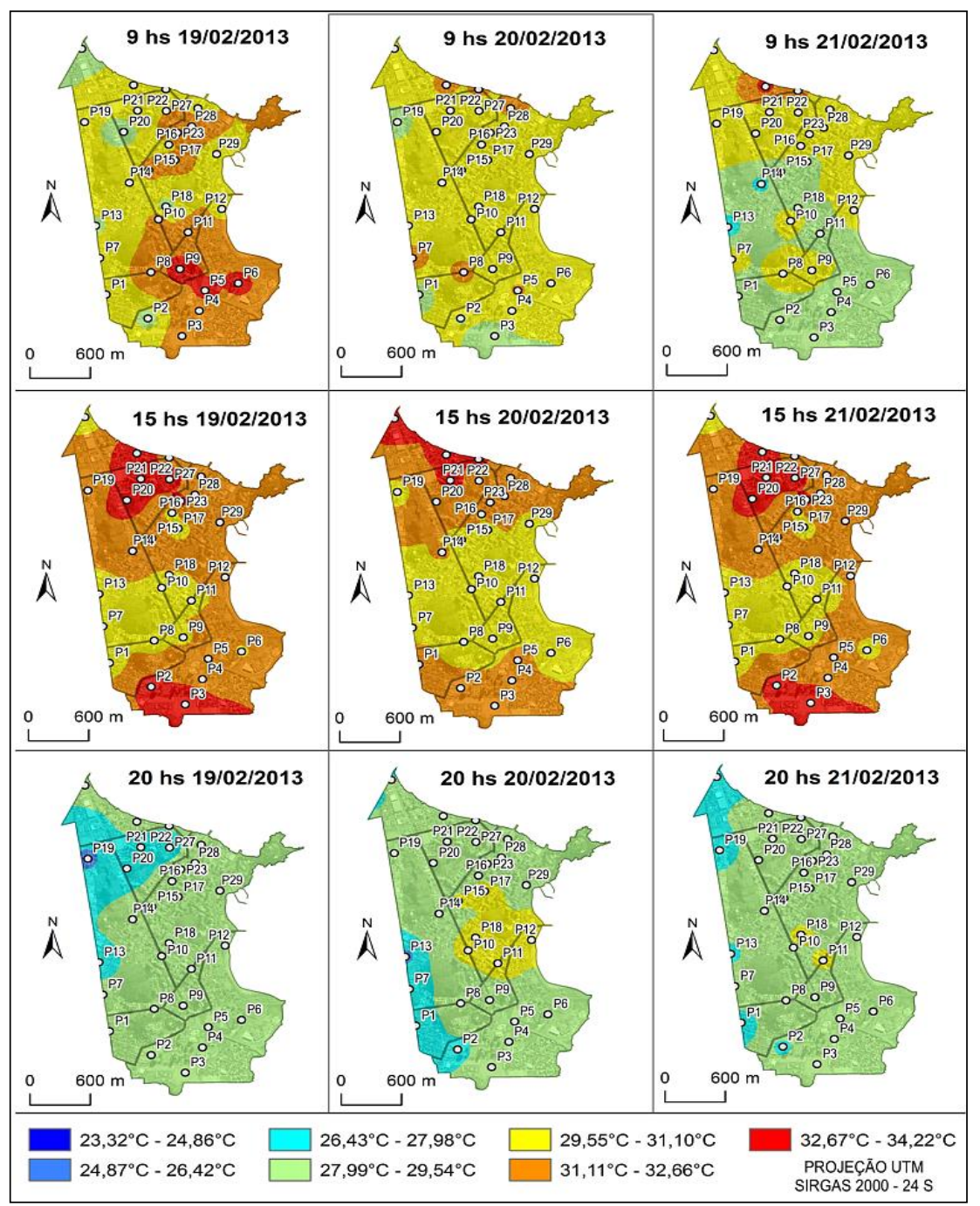

Figura 06: Variação espaço temporal da temperatura do ar durante o primeiro campo na RPC.

As porções mais aquecidas ao norte (transecto 4 e 5) e sul (transecto 1 e 2), compõem os núcleos térmicos.

O primeiro está localizado ao norte, com temperaturas do ar entre $33,4^{\circ} \mathrm{C}$ a $34,2^{\circ} \mathrm{C}$ e formado por P20, P21, P22, P23, P24, P25, P26 e P28 (transectos 4 e 5 ).

Nessa porção, o núcleo térmico localizado ao norte, há concentração de edificações verticalizadas que contribuem para o aprisionamento do ar dificultando a ventilação e, consequentemente, a manutenção de valores térmicos mais altos, devido à inércia térmica e à produção de calor pelos edifícios que possuem elevada capacidade de armazenamento e conservação 
de calor, aliado a circulação de veículos, comportamento semelhante ao observado por Brandão (1996; 2003).

O núcleo térmico que fica na parte sul (transecto 1 e 2) da área em estudo é constituído pelos pontos P2, P3, P5, P6 e P9, com temperaturas do ar entre $32,9^{\circ} \mathrm{C}$ a $33,9^{\circ} \mathrm{C}$.

No núcleo térmico localizado ao sul da área em estudo, seu surgimento está relacionado aos materiais utilizados na construção das edificações, há pouca quantidade de área verde e há grande circulação de veículos no entorno da 3ª Ponte, que liga o município de Vitória ao de Vila Velha; condições que contribuem para a manutenção dos elevados valores de temperatura do ar. Yoshino (1991) destaca que o fluxo de calor gerado por atividades antrópicas, como a intensa circulação de veículos automotores, bem como, o uso de aparelhos de ar condicionado, podem contribuir para o aquecimento da atmosfera nesses locais, condição semelhante ao observado no segundo núcleo térmico.

O aquecimento do tecido urbano às 9 horas local é influenciado diretamente pelo posicionamento do Sol e pelas características de uso e ocupação da terra, o que acarreta no aquecimento mais acentuado destas áreas. Abaixo na Tabela 04 é possível observar a amplitude térmica às 09 horas nos dias de coleta de dados em campo.

Tabela 04: Amplitude térmica às $9 \mathrm{~h}$ associados à direção e velocidade do vento e sistema atmosférico atuante.

\begin{tabular}{ccccc}
\hline Dia & $\begin{array}{c}\text { Amplitude } \\
\text { Térmica }\end{array}$ & Direção do Vento & $\begin{array}{c}\text { Velocidade do } \\
\text { Vento }\end{array}$ & $\begin{array}{c}\text { Sistema } \\
\text { Atmosférico }\end{array}$ \\
\hline $19 / 02 / 13$ & $6,1^{\circ} \mathrm{C}$ & $\mathrm{N}, \mathrm{NO}$ & $2,7-5,8 \mathrm{~m} / \mathrm{s}$ & ASAS \\
\hline $20 / 02 / 13$ & $3,4^{\circ} \mathrm{C}$ & $\mathrm{NNO}, \mathrm{NO}, \mathrm{NE}$ & $0,9-4,0 \mathrm{~m} / \mathrm{s}$ & ASAS \\
\hline $21 / 02 / 13$ & $6,0^{\circ} \mathrm{C}$ & $\mathrm{O}, \mathrm{NO}, \mathrm{N}$ & $0,4-4,0 \mathrm{~m} / \mathrm{s}$ & ASAS \\
\hline
\end{tabular}

Fonte: Pesquisa em campo nos dias 19,20 e 21/02/2013; CPTEC/INPE (2013); INMET (2013).

Pela manhã, a maior amplitude térmica ocorreu nos dias 19/02 com $6,1^{\circ} \mathrm{C}$ e 21/02 com 6,0․ A diferença no dia 19/02 foi estabelecida por P9 $\left(33,9^{\circ} \mathrm{C}\right)$ e P20 $\left(27,8^{\circ} \mathrm{C}\right)$. No dia 21/02 foi estabelecido por P25 $\left(33,3^{\circ} \mathrm{C}\right)$ e por P13 $\left(27,3^{\circ} \mathrm{C}\right)$. A amplitude térmica mais baixa no dia 20/02/2013 foi encontrado no $\mathrm{P} 27\left(32^{\circ} \mathrm{C}\right)$ e $\mathrm{P} 3\left(28,6^{\circ} \mathrm{C}\right)$ e está relacionado à presença de nuvens no início 
da manhã, carregadas de umidade, ocasionado pela maritimidade, tal processo contribuiu para que a radiação não atingisse a superfície diretamente, contribuindo para um aquecimento mais lento do tecido urbano.

No período vespertino, às 15h, nos três dias do experimento, na porção norte e sul da área em estudo, os núcleos térmicos ficaram mais característicos, conforme pode ser observado na Figura 06.

O maior valor de temperatura registrado no verão foi de $34,2^{\circ} \mathrm{C}$ por P20 às $15 \mathrm{~h}$ do dia 19/02/2013. Este comportamento pode estar relacionado a alguns fatores, tais como, o fluxo de veículos na Av. Reta da Penha, a ausência de vegetação no entorno, prédios de até 7 pavimentos com fachadas de alvenaria e vidros, a exemplo, do prédio da Petrobrás, que é todo de vidro. Estes materiais corroboram para que haja o aquecimento da atmosfera e consequentemente a elevação da temperatura do ar (OKE,1974).

Às 15 horas local, na porção centro-oeste e centro-leste, registraram-se os menores valores de temperatura do ar entre $29,4^{\circ} \mathrm{C}$ a $31,0^{\circ} \mathrm{C}$ nos pontos $\mathrm{P} 7$, P8, P9, P10, P11 (transecto 2) e P13, P16, P17, P18 e P19 (transecto 3 e 4) com temperatura do ar entre $30,1^{\circ} \mathrm{C}$ a $31,1^{\circ} \mathrm{C}$ (Figura 06). Estes locais são influenciados diretamente pelo sombreamento causado pelos maciços e colinas costeiras e pelos edifícios, impedindo que a radiação atinja a superfície em várias áreas, retardando o armazenamento de calor.

Pela tarde, às $15 \mathrm{~h}$, os gradientes térmicos foram de $4,1^{\circ} \mathrm{C}, 4,2^{\circ} \mathrm{C}$ e 4,0ํㅡ, para os dias 19/02, 20/02 e 21/02/2013, respectivamente, havendo uma redução média de $2^{\circ} \mathrm{C}$ na temperatura em relação às 09 horas da manhã mesmo sob a atuação da ASAS e no verão, fato que pode estar relacionado ao aumento da velocidade do vento, conforme pode ser observado na Tabela 05.

Tabela 05: Gradientes térmicos às $15 \mathrm{~h}$ associados à direção e velocidade do vento e sistema atmosférico atuante.

\begin{tabular}{ccccc}
\hline Dia & Gradiente Térmico & Direção do Vento & Velocidade do Vento & Sistema Atmosférico \\
\hline $19 / 02$ & $4,1^{\circ} \mathrm{C}$ & NE, NNE, N & $6,3-7,6 \mathrm{~m} / \mathrm{s}$ & ASAS \\
\hline $20 / 02$ & $4,2^{\circ} \mathrm{C}$ & NNE, NE, N & $3,1-6,7 \mathrm{~m} / \mathrm{s}$ & ASAS \\
\hline $21 / 02$ & $4,0^{\circ} \mathrm{C}$ & $\mathrm{NE}, \mathrm{ENE}, \mathrm{NNE}$ & $2,7-4,2 \mathrm{~m} / \mathrm{s}$ & ASAS
\end{tabular}

Fonte: Pesquisa em campo nos dias 19,20 e 21/02/2013; CPTEC/INPE (2013); INMET (2013). 
A amplitude térmica no dia 19/02 às 15 horas foi estabelecida em P20 $\left.34,2^{\circ} \mathrm{C}\right)$ e P13 $\left(30,1^{\circ} \mathrm{C}\right)$. No dia 20/02 foi estabelecido por P24 $\left(33,3^{\circ} \mathrm{C}\right)$ e P8 $\left(29,4^{\circ} \mathrm{C}\right)$. No dia 21/02 a amplitude térmica foi estabelecida por P20 $\left(34,1^{\circ} \mathrm{C}\right)$ e P13 $\left(30,1^{\circ} \mathrm{C}\right)$ (Figura 06). É valido ressaltar que as magnitudes dos campos térmicos durante o dia no verão foram semelhantes aos encontrados por Amorim (2000), mesmo que o local de pesquisa da autora não seja uma área próxima ao litoral, fato que pode corroborar para intensificação do desconforto térmico.

Com temperatura do ar variando entre $29,5^{\circ} \mathrm{C}$ a $30,1^{\circ} \mathrm{C}$ durante os três dias dos experimentos, P9, P10, P11, P12, P15, P16, P17 e P18 (transecto 2 e 3) configuram-se em locais de produção de calor noturno. Nesses pontos, localizados na porção centro-leste da área em estudo, o aquecimento do local pode estar relacionado às modificações do balanço energético no meio urbano, que pode ter sua evolução noturna dirigida de maneira mais preponderante pelas características e constituição química da atmosfera (MACHADO, 2011). À medida que as paredes dos edifícios e superfícies cobertas por asfalto esfriam, parte da energia radiativa perdida pode estar sendo absorvida pelo ar, devido à presença de poluentes e vapor d'água, apresentando um resfriamento mais lento (MACHADO, op. cit.). As variedades da geometria dos prédios dessa área funcionam como obstáculo para o vento, modificando o seu fluxo natural, aumentando a turbulência do ar, dificultando à ação do vento na dispersão do calor para longe. Também, nesse horário, há grande circulação de veículos na região que, consequentemente, emite calor e contribui para a turbulência dos níveis inferiores do ar (PAZERA JUNIOR, 1976), favorecendo o aumento das temperaturas do ar.

Às 20h, observa-se que as áreas que formavam os núcleos térmicos às 15 , o primeiro núcleo na parte norte com temperaturas do ar entre $33,4^{\circ} \mathrm{C}$ a $34,2^{\circ} \mathrm{C}$ e formado por P20, P21, P22, P23 e P25 (transectos 4 e 5), e sul com temperaturas do ar variando entre $32,9^{\circ} \mathrm{C}$ a $33,9^{\circ} \mathrm{C}$ e constituídos por $\mathrm{P} 2, \mathrm{P} 3 \mathrm{e}$ P4 (transecto 1 e 2) perderam calor, em relação aos pontos situados na região centro-leste, conforme supracitado. Este comportamento pode estar 
CONTRIBUIÇÃO À COMPREENSÃO DO CAMPO TÉRMICO DA REGIONAL PRAIA DO CANTO, EM VITÓRIA (ES) PELA METODOLOGIA DE TRANSECTOS

relacionado ao padrão de uso e ocupação da terra, troca de calor com a atmosfera, direção e velocidade do vento e a maritimidade.

À noite às 20h, a maior amplitude térmica entre os pontos ocorreu no dia 20/02 com 4, $0^{\circ} \mathrm{C}$, sendo resultante por P11 $\left(30,1^{\circ} \mathrm{C}\right)$ e P13 $\left(26,1^{\circ} \mathrm{C}\right)$. Nos demais dias os gradientes térmicos foram: para o dia $19 / 02,3,6^{\circ} \mathrm{C}$, diferença entre P11 $\left(29,6^{\circ} \mathrm{C}\right)$ e P19 $\left(26,0^{\circ} \mathrm{C}\right)$. Para o dia 21/02, 2,3ํㅡ, diferença entre P18 (Rua Eugênio Neves: $\left.29,8^{\circ} \mathrm{C}\right)$ e P19 $\left(27,5^{\circ} \mathrm{C}\right)$.

Nos dias de experimento no período noturno, P19 foi o ponto que registrou as menores temperaturas, fato que pode estar relacionado às seguintes condições: o local é pavimento com asfaltado, há poucos prédios ao entorno e a noite a circulação de veículo é bem menor em relação ao dia, situação que pode ser preponderante para que a liberação do fluxo de calor (resfriamento) seja mais rápida que os demais pontos. Abaixo é possível visualizar na Tabela 06 a amplitude térmica às 20h, onde fica evidente, a relação direta entre a velocidade do vento e a redução dos índices térmicos, quanto maior a velocidade do vento no período noturno menor foram os gradientes térmicos.

Tabela 06: Amplitude Térmica às $20 \mathrm{~h}$ associados à direção e velocidade do vento e sistema atmosférico atuante.

\begin{tabular}{ccccc}
\hline Dia & $\begin{array}{c}\text { Amplitude } \\
\text { Térmica }\end{array}$ & $\begin{array}{c}\text { Direção do } \\
\text { Vento }\end{array}$ & $\begin{array}{c}\text { Velocidade do } \\
\text { Vento }\end{array}$ & $\begin{array}{c}\text { Sistema } \\
\text { Atmosférico }\end{array}$ \\
\hline $19 / 02$ & $3,6^{\circ} \mathrm{C}$ & $\mathrm{N}, \mathrm{NE}$ & $1,3-2,7 \mathrm{~m} / \mathrm{s}$ & ASAS \\
\hline $20 / 02$ & $4,0^{\circ} \mathrm{C}$ & $\mathrm{NNE}$ & $0,4-1,8 \mathrm{~m} / \mathrm{s}$ & ASAS \\
\hline $21 / 02$ & $2,3^{\circ} \mathrm{C}$ & $\mathrm{N}$ & $2,2-3,1 \mathrm{~m} / \mathrm{s}$ & ASAS \\
\hline
\end{tabular}

Fonte: Pesquisa em campo nos dias 19,20 e 21/02/2013.

CPTEC/INPE (2013); INMET (2013). Organizado pelo autor.

\subsection{Condições Atmosféricas - Levantamento de Campo II (Inverno) - entre os dias 27 a 28 de junho de 2013 (inverno)}

No domínio da ASAS verificou-se condições meteorológicas com céu claro e poucas nuvens durante o dia e a noite, tempo estável e ventos fracos, situação que permitiu a realização dos experimentos em campo nos dias 27/06/2013 e 28/06/2013 (Figura 07). Entre os dias 25/06/2013 a 30/06/2013 a 
pressão atmosférica manteve-se elevada com média de 1014,4hPa, e umidade relativa do ar manteve-se elevada com média de 72,8\% (INMET, 2013).

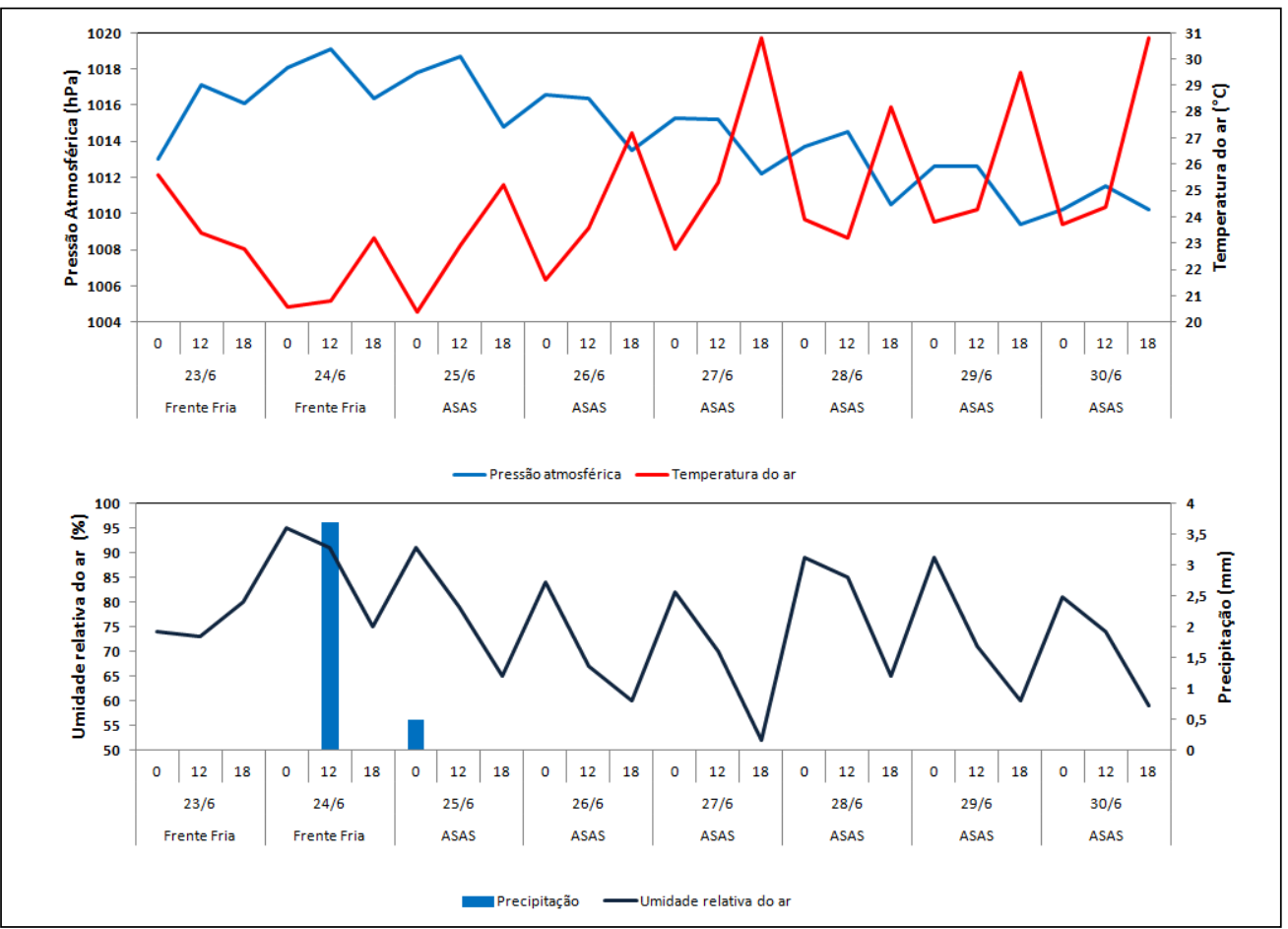

Figura 07: Evolução temporal da pressão atmosférica em superfície, da temperatura do ar, umidade relativa do ar e precipitação no período de 23/06/2013 a 30/06/2013. Fonte de dados: INMET (2013).

No dia 27/06/2013 a atuação do Sistema de Alta Pressão Atmosférica (ASAS) dificultou a formação de nuvens. Neste dia a temperatura média foi de $26,3^{\circ} \mathrm{C}$ e a máxima de $30,8^{\circ} \mathrm{C}$. A umidade relativa do ar média foi de aproximadamente $68 \%$ e direção de vento predominante do norte (INMET, 2013).

No dia 28/06/2013 pela manhã, as temperaturas do ar ficaram um pouco mais baixa que no dia anterior, com temperatura média de $25,1^{\circ} \mathrm{C}$ e máxima de $28,2^{\circ} \mathrm{C}$, sendo observada uma amplitude térmica de $2,6^{\circ} \mathrm{C}$ em relação à máxima do dia anterior. A umidade relativa do ar média foi de aproximadamente de $79 \%$ e a direção do vento variando entre norte, sul e leste. Entretanto, às 15 horas, observou-se mudança na direção do vento e queda das temperaturas registradas pela estação meteorológica do INMET (2013). A mudança nas condições do tempo esteve associada a uma frente fria no oceano Atlântico, aproximando-se do sul do Espírito Santo. Porém, esta não 
atingiu a área em estudo, devido ao estabelecimento da ASAS sobre o estado (CPTEC/INPE, 2013).

\subsection{Análise da temperatura do ar na RPC - Levantamento de Campo II}

O comportamento da temperatura do ar na Regional V - Praia do Canto (RPC) entre os dias 27/06, 28/06 às 9, 15 e às 20 horas foram realizadas por meio de transectos móveis e encontram-se na Figura 08. Neste período, a temperatura do ar esteve entre $23,3^{\circ} \mathrm{C}$ a $33,0^{\circ} \mathrm{C}$, apresentando uma amplitude média de $9^{\circ} \mathrm{C} /$ dia. Os maiores valores de temperatura do ar foram registrados às $15 \mathrm{~h}$ nos dois dias das atividades de campo. Os menores valores de temperatura do ar foram registrados na manhã do dia 28/06/2013.

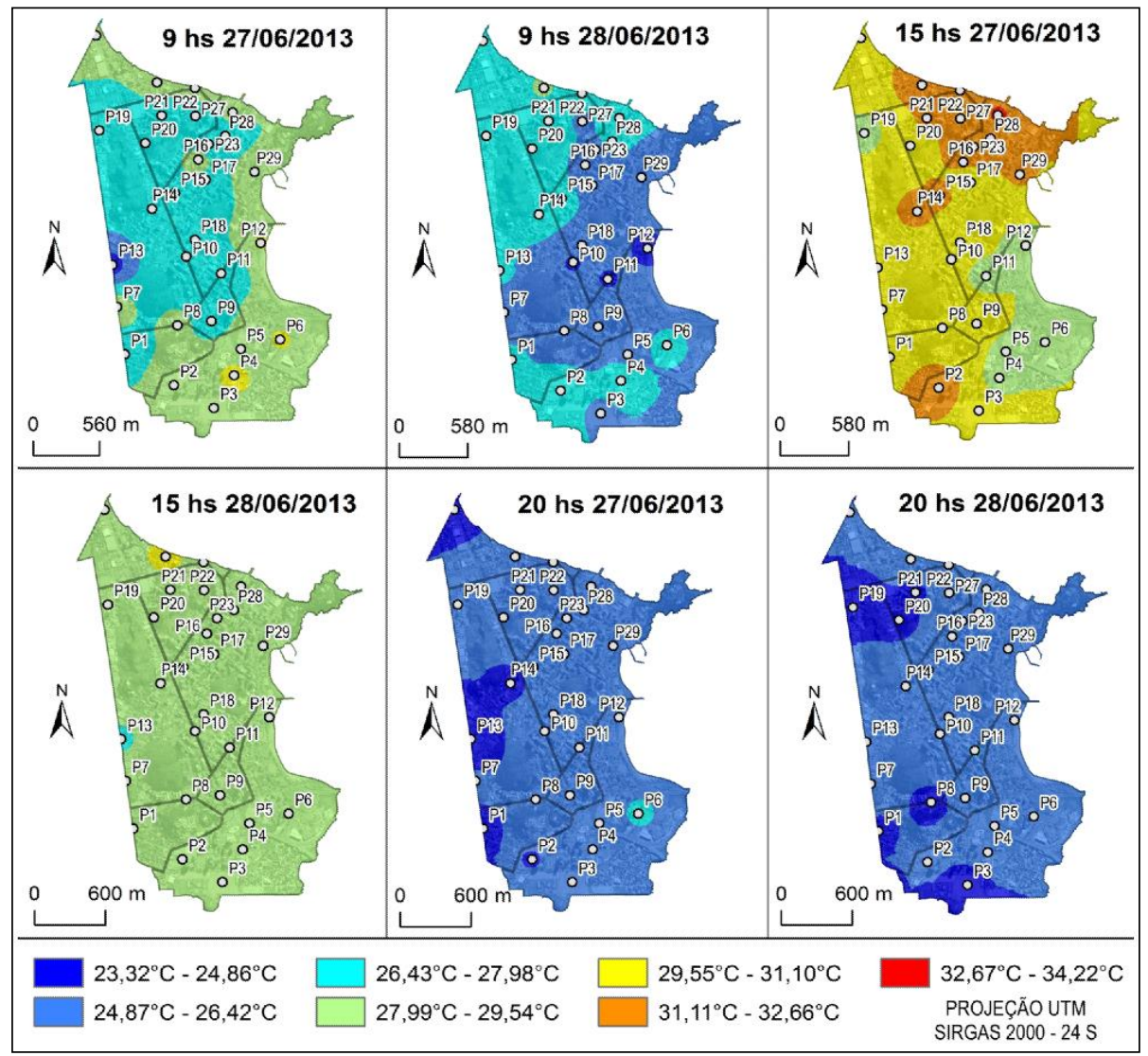

Figura 08: Variação espaço temporal da temperatura do ar durante o segundo campo na RPC.

Novamente observa-se a presença de núcleos térmicos. O primeiro núcleo térmico localizado a norte, apresenta temperaturas do ar entre $31,2^{\circ} \mathrm{C}$ a $33^{\circ} \mathrm{C}$ e é formado por P21, P22, P23, P25, P26, P27, P28 e P29 (transectos 4 e 5). Entretanto, observa-se o surgimento de outro núcleo térmico com 
temperatura do ar entre $31,2^{\circ} \mathrm{C}$ a $31,7^{\circ} \mathrm{C}$ localizado a centro-norte na área em estudo (transectos 3 e 4) e formado por P14, P15 e P16.

É necessário ressaltar que os núcleos térmicos localizados ao norte da área em estudo, tanto no campo I, quanto no campo II, possuem uma concentração de edificações verticalizadas que contribuem para 0 aprisionamento do ar dificultando a ventilação e, consequentemente, a manutenção de valores térmicos mais altos, devido à inércia térmica e à produção de calor pelos edifícios que possuem elevada capacidade de armazenamento e conservação de calor, aliado à grande circulação de veículos.

O núcleo térmico que fica na parte sul (transecto 1 e 2) da área em estudo apresentou mudança na configuração em relação ao primeiro experimento em fevereiro de 2013. No primeiro campo era constituído pelos pontos $\mathrm{P} 2, \mathrm{P} 3, \mathrm{P} 4, \mathrm{P} 5$ e P9, no segundo campo o núcleo térmico passa a ser constituído pelos pontos P1, P2, P3, P7, P8 e P9 com temperaturas do ar entre $30,6^{\circ} \mathrm{C}$ e $32,5^{\circ} \mathrm{C}$.

No núcleo térmico localizado ao sul da área em estudo, seu surgimento está relacionado aos materiais utilizados na construção das edificações, há pouca quantidade de área verde e há grande circulação de veículos no entorno da 3a Ponte, que liga o município de Vitória ao de Vila Velha; condições que contribuem para a manutenção dos elevados valores de temperatura do ar. Condição similar foi observada no levantamento de campo realizado no verão em fevereiro de 2013.

Os núcleos térmicos foram mais intensos no dia 27/06 em função da presença da ASAS sobre a área em estudo. Destaca-se que: tanto no campo I, quanto no campo II, os núcleos térmicos foram mais intensos quando a ASAS estava atuando sobre o Estado. Os pesquisadores Brandão (2003) e Assis (2010), observaram que as maiores influências do "tecido urbano" na temperatura do ar foram verificadas sob influência da ASAS, quando a intensidade dos gradientes térmicos fora maior, condição também observada nessa pesquisa durante os experimentos realizados. 
No dia 28/06/2013 as temperaturas foram menores em função da mudança da direção do vento, causada por uma área alongada de baixa pressão (cavado) que estava associada a uma frente fria no oceano Atlântico próximo ao sul do estado do Espírito Santo (INPE/CPTEC, 2013). Com a condição sinótica apresentada no dia 28/06/2013, observa-se que os núcleos térmicos às 9 horas e às 15 horas na parte sul e norte, são minimizados (Figura 08). Mediante o exposto, observa-se que a condição sinótica terá uma influência direta sobre a temperatura do ar no tecido urbano, ou seja, distintos sistemas atmosféricos influenciaram na magnitude dos fenômenos do clima urbano (CORREA et al.,2015), como por exemplo, a Ilha de Calor.

Às 9 horas da manhã do dia 28/06 registraram-se as menores temperaturas na porção centro-leste na RPC, diferentemente daquelas do dia $27 / 06$, onde as menores temperaturas foram registradas na porção centrooeste.

A amplitude térmica pela manhã no dia $27 / 06$ foi de $6,0^{\circ} \mathrm{C}$. A diferença ocorreu por P4 $\left(30,2^{\circ} \mathrm{C}\right)$ e P13 $\left(24,2^{\circ} \mathrm{C}\right)$. No dia $28 / 06$ o gradiente térmico constituiu em $3,9^{\circ} \mathrm{C}$, situado por P25 $\left(33,3^{\circ} \mathrm{C}\right)$ e P12 $\left(24,4^{\circ} \mathrm{C}\right)$. As amplitudes térmicas encontradas na pesquisa mostram relação direta com o sistema atmosférico e ocupação do solo, independente da estação do ano (Tabela 07).

Tabela 07: Amplitude térmica às $9 \mathrm{~h}$ associados à direção e velocidade do vento e sistema atmosférico atuante

\begin{tabular}{ccccc}
\hline Dia & $\begin{array}{c}\text { Amplitude } \\
\text { Térmica }\end{array}$ & $\begin{array}{c}\text { Direção do } \\
\text { Vento }\end{array}$ & $\begin{array}{c}\text { Velocidade do } \\
\text { Vento }\end{array}$ & $\begin{array}{c}\text { Sistema } \\
\text { Atmosférico }\end{array}$ \\
\hline $27 / 06$ & $6,0^{\circ} \mathrm{C}$ & $\begin{array}{c}\text { NNO, NO, } \\
\text { ONO }\end{array}$ & $0,9-4,5 \mathrm{~m} / \mathrm{s}$ & ASAS \\
\hline $28 / 06$ & $3,9^{\circ} \mathrm{C}$ & SO, SSE, ENE, & $0,9-1,8 \mathrm{~m} / \mathrm{s}$ & ASAS/Frente Fria
\end{tabular}

Fonte: Pesquisa em campo nos dias 27/6 e 27/06/2013; CPTEC/INPE (2013); INMET (2013).

Às 15 horas, são observadas as alterações no campo térmico em relação às 9 horas (Figura 08). Os núcleos térmicos continuam na porção norte e sul. Porém, o primeiro que está situado ao norte, amplia a sua extensão, para oeste até o P14 quase "conectando-se" com o segundo núcleo térmico. Porém, devido à presença das colinas e maciços costeios que fazem sombreamento 
sobre o P7, inferindo diretamente sobre a temperatura do ar, acarretando no interrompendo da continuidade do núcleo.

No segundo horário, verificaram-se a centro leste da área em estudo os menores valores de temperatura do $\operatorname{ar}\left(24,4^{\circ} \mathrm{C}\right.$ a $\left.25^{\circ} \mathrm{C}\right)$ (Figura 08), formando áreas mais arrefecidas (transecto 1 e 2). Estes locais são influenciados diretamente pelo sombreamento causado pelos edifícios e pelo efeito da maritimidade. O efeito de sombreamento dificulta que a radiação atinja a superfície completamente, retardando o armazenamento de calor, corroborando para que as temperaturas do ar sejam menores. Comportamento similar foi verificado na mesma região durante o campo de verão, entre os dias 19 a 21 de fevereiro de 2013. Em relação ao padrão observado para a região leste e parte da central da área em estudo, nota-se que a proximidade com oceano Atlântico influencia diretamente a temperatura do ar, fazendo com que ela permaneça mais amena durante o dia. Este comportamento foi observado nos dois levantamentos de campo.

Sobre o efeito de sombreamento causado por edifícios, Brandão (2003) afirma que a superfície que é sombreada depende da altura do edifício e do ângulo de inclinação, sendo este maior no inverno, assim, o tempo de sombreamento da superfície é sensivelmente aumentado, favorecendo o aumento de umidade local, condições que podem favorecer o surgimento de microrganismos causadores de doenças.

No período da tarde, às 15 horas, foram registrados $4,8^{\circ} \mathrm{C}$ e $4,7^{\circ} \mathrm{C}$ de amplitude térmica para os dias 27/06 e 28/06/2013, respectivamente, conforme pode ser averiguado na Tabela 08. A diferença no dia 27/06 foi estabelecida por P27 $\left(33,0^{\circ} \mathrm{C}\right)$ e P6 $\left(28,2^{\circ} \mathrm{C}\right)$. No dia $28 / 06 / 2013$ foi situado por P20 $\left(31,7^{\circ} \mathrm{C}\right)$ e P23 $\left(27,0^{\circ} \mathrm{C}\right)$ (Figura 07).

Tabela 08: Amplitude Térmica às $15 \mathrm{~h}$ associados à direção e velocidade do vento e sistema atmosférico atuante.

\begin{tabular}{ccccc}
\hline Dia & $\begin{array}{c}\text { Amplitude } \\
\text { Térmica }\end{array}$ & $\begin{array}{c}\text { Direção do } \\
\text { Vento }\end{array}$ & $\begin{array}{c}\text { Velocidade do } \\
\text { Vento }\end{array}$ & $\begin{array}{c}\text { Sistema } \\
\text { Atmosférico }\end{array}$ \\
\hline $27 / 06$ & $4,8^{\circ} \mathrm{C}$ & NNE, NNO, N & $3,6-5,8 \mathrm{~m} / \mathrm{s}$ & ASAS \\
\hline $28 / 06$ & $4,7^{\circ} \mathrm{C}$ & SE, ESSE & $1,3-3,1 \mathrm{~m} / \mathrm{s}$ & ASAS/Frente Fria \\
\hline
\end{tabular}

Fonte: Pesquisa em campo nos dias $27 / 6$ e 27/06; CPTEC/INPE (2013); INMET (2013).

Organizado pelo autor. 
Fica evidente às $15 \mathrm{~h}$, que mesmo com a redução das temperaturas do ar a amplitude térmica foi alta no segundo dia de experimento, o que evidência relação com uso e ocupação da terra e o aquecimento da superfície, também, mostra que o resfriamento do ar é gradativo devido a mudança da direção do vento.

Às 20 horas, são observadas alterações no campo térmico em relação às 15 horas na RPC. No terceiro horário dos experimentos, a porção leste da área em estudo, que anteriormente, nos dois horários, ás 09 horas e às 15 horas, proporcionava os menores valores de temperatura, apresenta o registro de maiores temperaturas do ar, mostrando boa correlação com uso e ocupação da terra. Essa porção é densamente ocupada, asfaltada e com padrão de construção predominante vertical composta por edifícios acima de 10 pavimentos. Tal situação corrobora para que parte da energia radiativa perdida possa está sendo absorvida pelo ar, devido à presença de poluentes e vapor d'água (Machado, 2011). Por este motivo, esta porção da RPC (transecto 2 e 3), apresenta um resfriamento mais lento, favorecendo o aumento da temperatura do ar (Figura 08).

A área mais aquecida no período noturno neste segundo campo, com temperatura do ar entre $25,9^{\circ} \mathrm{C}$ a $26,7^{\circ} \mathrm{C}$, foi localizado na mesma região (centro leste - transecto 1, 2 e 3) do primeiro campo às 20 horas. No primeiro campo entre os dias 19 a 31 de fevereiro de 2013, a localização dos pontos foi a centro leste da área em estudo e era constituído por P9, P10, P11, P12, P15, P16, P17 e P18; porém, no segundo experimento, a área mais aquecida no período noturno, foi constituída por P5, P6, P11, P12 e P18.

Conforme mencionado no item sobre temperatura do ar nos resultados do campo I, as geometrias dos prédios dessas áreas podem funcionar como obstáculo para o vento, dificultando à ação do vento na dispersão do calor. Também, nesse horário, há grande circulação de veículos na região, consequentemente, emitem calor e contribuem para a turbulência dos níveis inferiores do ar (PAZERA JUNIOR, 1976), dificultando a dispersão térmica perto ao solo em direção às camadas superiores, podendo contribuir para o aumento das temperaturas. 
A amplitude térmica (Tabela 09) às 20 horas no dia 27/06/2013 foi de

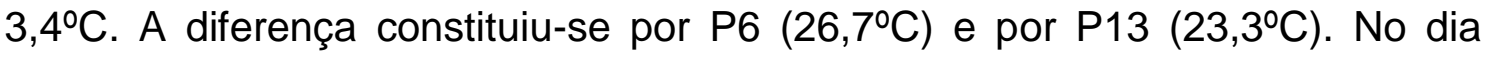
$28 / 06$ a amplitude térmica foi de $2,4^{\circ} \mathrm{C}$ que foi estabelecido entre P11 $\left(26,5^{\circ} \mathrm{C}\right)$ e P20 $\left(2,4^{\circ} \mathrm{C}\right)$.

Tabela 09: Amplitude térmica às $20 \mathrm{~h}$ associados à direção e velocidade do vento e sistema atmosférico atuante.

\begin{tabular}{ccccc}
\hline Dia & $\begin{array}{c}\text { Amplitude } \\
\text { Térmica }\end{array}$ & $\begin{array}{c}\text { Direção do } \\
\text { Vento }\end{array}$ & $\begin{array}{c}\text { Velocidade do } \\
\text { Vento }\end{array}$ & $\begin{array}{c}\text { Sistema } \\
\text { Atmosférico }\end{array}$ \\
\hline $27 / 06 /$ & $3,4^{\circ} \mathrm{C}$ & $\mathrm{N}$ & $0,4-1,3 \mathrm{~m} / \mathrm{s}$ & ASAS \\
\hline $28 / 06 /$ & $2,4^{\circ} \mathrm{C}$ & SE, E & $1,8-3,1 \mathrm{~m} / \mathrm{s}$ & ASAS/Frente Fria \\
\hline
\end{tabular}

Fonte: Pesquisa em campo nos dias 27/6 e 28/06; CPTEC/INPE (2013); INMET (2013). Organizado pelo autor.

Por fim, a amplitude térmica nos dois experimentos, campo I e campo II, seguem a dinâmica atmosférica dos episódios sazonais analisados, sendo os sistemas atmosféricos de escala sinótica, neste caso, a ASAS, e o posicionamento geográfico, no caso, a proximidade com 0 Atlântico (maritimidade), fatores determinantes no comportamento térmico da área em estudo. Em relação ao estudo de clima urbano em cidade costeira, Brandão (2003) observou para o Rio de Janeiro que às $15 \mathrm{~h}$ e às $21 \mathrm{~h}$ são registradas as maiores amplitudes térmicas durante a atuação da ASAS. Porém, nesta pesquisa observou-se que são as 09h e 15h o registro das maiores amplitudes térmicas.

\section{CONSIDERAÇÕES FINAIS}

Nesta pesquisa foi possível avaliar o comportamento térmico em diferentes pontos da Regional Praia do Canto (RCP) no município de Vitória, tanto no período chuvoso (verão), quanto no menos chuvoso (inverno), por meio de dados levantados pela técnica do transecto móvel, onde foram averiguadas que as mudanças de uso e de ocupação da terra, associadas com as características do relevo (maciços e colinas costeiras), bem como com a dinâmica atmosférica, influenciam diretamente as variáveis meteorológicas no sítio urbano, neste caso, a temperatura do ar. 
Os resultados mostram que tanto no verão, quanto no inverno, às áreas mais aquecidas ficaram bem definidas. Estas áreas correspondem aos núcleos térmicos, concentração de pontos (localidades próximas) com o registro de maiores temperaturas do ar dentro de uma mesma realidade urbana. Nessas localidades, nos dois períodos (verão/inverno), observou, que as edificações verticalizadas tem contribuído para o aprisionamento do ar, dificultando a ventilação e consequentemente, a manutenção de valores térmicos mais altos, devido à inércia térmica e à produção de calor pelos edifícios que possuem elevada capacidade de armazenamento e conservação de calor, aliado à grande circulação de veículos e superfície cobertas por asfaltos, condições que inibem a dispersão térmica perto a superfície em direção às camadas superiores, podendo contribuir para o aumento de temperatura.

Os maiores registros de gradientes térmicos foram observados às 9 horas e às 15 horas, tanto no verão, quanto no inverno. As maiores influências do "tecido urbano" na temperatura do ar foram verificadas sob influência da ASAS, quando a intensidade dos gradientes, nos núcleos térmicos foram maiores. Percebeu-se que os efeitos da maritimidade exercem um papel importante no comportamento térmico. Porém, há necessidade de estudos mais aprofundados sobre essa relação.

Na porção centro-leste da Regional Praia do Canto observou-se até $3^{\circ} \mathrm{C}$ a menos nos períodos vespertinos em relação aos pontos localizados nas porções norte e sul. Os pontos da porção centro-leste sofrem influência direta dos efeitos da maritimidade e dos arranjos dos prédios que formam sombreamento sobre os pontos de coleta, condição que favorece o registro de menores temperaturas.

Sugere-se que com este artigo outras propostas que venham a contribuir para o entendimento do clima urbano e seus fenômenos no município de Vitória e Região Metropolitana, bem como, o clima urbano de região litorâneas de clima tropical: estudo sobre os impactos das estruturas urbanas sobre a circulação dos ventos e sobre o balanço de radiação; estudo de modelagem numérica da atmosférica com o intuito de observar os efeitos da brisa marítima 
CONTRIBUIÇÃO À COMPREENSÃO DO CAMPO TÉRMICO DA REGIONAL PRAIA DO CANTO, EM VITÓRIA (ES) PELA METODOLOGIA DE TRANSECTOS

e continental sobre o campo térmico; o Sistema Clima Urbano da Região Metropolitana da Grande Vitória

\section{REFERÊNCIAS BIBLIOGRÁFICAS}

ALCOFORADO, M.J. Aplicação da climatologia ao planejamento urbano. Alguns apontamentos. Finisterra. Revista Portuguesa de Geografia, 67-68, 1999, p. 83-94.

ALVES, E.D.L.; BIUDES, M.S.; VECCHIA, F.A.S. Interpolação espacial na climatologia: Análise dos critérios que precedem sua aplicação. Revista Geonorte, Edição Especial 2, V.1, N.5, p.606 - 618, 2012

AMORIM, M. C. C. T. O. Clima urbano de Presidente Prudente/SP. Tese (Doutorado em Geografia) - Faculdade de Filosofia Letras e Ciência Humanas - USP. São Paulo, 2000. 378p.

ANDRADE, $H$. $O$ clima urbano: Natureza, escalas de análise e aplicabilidade. Finisterra, Lisboa, v. 50, n. 80, 2005. pp. 67-91.

ASSIS, E. S.: A abordagem do clima urbano e aplicações no planejamento da cidade: reflexões sobre uma trajetória. In: ENCONTRO NACIONAL E IV ENCONTRO LATINO-AMERICANO SOBRE CONFORTO NO AMBIENTE CONSTRUÍDO, Maceió. Anais...Maceió: ANTAC, p. 92-101, 2005.

ASSIS, W. L. O sistema clima urbano do município de Belo Horizonte na perspectiva têmporo-espacial. Tese (Doutorado em Geografia) - Instituto de Geociências, Universidade Federal de Minas Gerais, Belo Horizonte, 2010, $299 f$.

BRANDÃO, A.M de P.M.O clima urbano da cidade do Rio de Janeiro. Tese (Doutorado em Geografia). Departamento de Geografia, FFLCH, Universidade de São Paulo, São Paulo, 1996. 362 p.

BRANDÃO, A. M. P. M. O clima urbano da cidade do Rio de Janeiro. In: Clima Urbano. Org. Mendonça, F; Monteiro, C.A de F. São Paulo: Contexto, 2003, p 121 - 153.

Centro de Previsão de Tempo e Estudos Climáticos - CPTEC. Análise Sinótica de Superfície dos dias 19/02 a 21/02 de 2013 e 27/06 a 28/06. Acesso em 28 de fevereiro. 2013. Disponível em: < http://www7.cptec.inpe.br/ rupload/arquivo/analise >.

CORREA, W.S.C. Comportamento dos elementos climáticos, temperatura e precipitação, no Município de Vitória (ES) no período de 1978 a 2007. Monografia (Bacharelado em Geografia). Universidade Federal do Espírito Santo, Vitória, 2011. 
CONTRIBUIÇÃO À COMPREENSÃO DO CAMPO TÉRMICO DA REGIONAL PRAIA DO CANTO, EM VITÓRIA (ES) PELA METODOLOGIA DE TRANSECTOS

CORREA, W.S.C.; NASCENTES, A.L.C.; VALE, C.C. Influência de distintos sistemas atmosféricos na temperatura de superfície do município de Vitória (ES). Revista Caminhos de Geografia. vol.16 n.53 Uberlândia, MG, 2015, p. 37-54.

COSTA, R. B. Adversidades climáticas em Vitória? Vitória, Instituto Histórico e Geográfico do Espírito Santo/ Prefeitura Municipal de Vitória, 1992.

FIALHO, E. S. Ilha de calor em cidade de pequeno porte: Caso de Viçosa, na Zona da Mata Mineira. Tese (Doutorado em Geografia Física), Faculdade de Filosofia, Letras e Ciências Humanas, Universidade Estadual de São Paulo, São Paulo, 2009, $248 f$.

GARTLAND, L. Ilhas de calor: como mitigar zonas de calor em áreas urbanas. São Paulo: Oficina de Textos, 2010. 248 p.

GÓMEZ, A. L., GARCIA, F. F. La isla de calor en Madrid: avance de un estudio del clima urbano. Estudios Geográficos, 45, n.174, p.5-34, eneromarzo 1984.1997.

Instituto Brasileiro de Geografia e Estatística - IBGE. Censo 2015. Disponível em: http://www.ibge.gov.br/cidadesat/topwindow.htm?1>. Acesso em 20 de fevereiro de 2015.

Instituto Capixaba de Pesquisa, Assistência Técnica e Extensão Rural INCAPER. Sistema de Informação Meteorológica (Previsão do Tempo). Disponível em: http://hidrometeorologia. incaper.es.gov.br/. Acesso em 22 de fevereiro de 2013.

Instituto Nacional de Meteorologia - INMET. Banco de Dados Meteorológico para Ensino e Pesquisa. Brasília, 2013.

IOCHINOSE, T., SIHIMODOZONO, K. H. Impact of anthropogenic heat on urban climate in Tokyo. Atmospheric Environment. V. 33. 1999, p.3897-3909.

JAUREGUI, E. The urban climate of Mexico City. Erdkunde, Berlin, v. 27, p. 289-307, 1973.

LANDSBERG, H. E. O Clima das Cidades. Revista do Departamento de Geografia, № 18, 2006, p. 95-111.

LEE, D. O. An analysis of recent trends in London's heat island. Weather. 47, 50-56. 1990.

LI, J., HEAP, A.D. A review of comparative studies of spatial interpolation methods in environmental sciences: Performance and impact factors. Ecological Informatics, n॰ 6, p. 228-241, 2011.

LOMBARDO, M. A. Ilha de calor nas metrópoles: o exemplo de São Paulo. São Paulo: Hucitec, 1985. 244p. 
CONTRIBUIÇÃO À COMPREENSÃO DO CAMPO TÉRMICO DA REGIONAL PRAIA DO CANTO, EM VITÓRIA (ES) PELA METODOLOGIA DE TRANSECTOS

LOWRY, W. P. Empirical estimation of urban effects on climate: a problem analysis. Journal of Applied Meteorology, 16, 1977: 129 - 153.

MACHADO, A.J. Fluxos radiativos da Av. Paulista, São Paulo - SP, discutidos a partir da análise das formas. Caderno Prudentino de Geografia, Presidente Prudente, n.33, v.2, p.21-41, ago./dez.2011.

MENDONÇA, F. de A. O clima e o planejamento urbano de cidade de porte médio e pequeno: proposição metodológica para estudo e aplicação à cidade de Londrina, PR. Tese (Doutorado em Geografia Física) - Faculdade de Filosofia, Letras e Ciências Humanas, Universidade de São Paulo, 1995. 322p.

MENDONÇA, F. de A. O estudo do clima urbano no Brasil - evolução, tendências e alguns desafios. In: MONTEIRO, C. A. F.; . (Org.). Clima urbano. São Paulo: Contexto, 2003, p. 175-192.

MONTEIRO C. A. F. Teoria e Clima Urbano. São Paulo, IGEOG/USP, 1976, $181 \mathrm{p}$.

Por um suporte teórico e prático para estimular estudos geográficos do clima urbano do Brasil. GeoSul. № 9, 1990, p.7140.

MONTEIRO, C. A. F. Teoria e clima urbano - um projeto e seus caminhos. In: MONTEIRO, C. A. F.; MENDONÇA, F. (Org.). Clima urbano. São Paulo: Contexto, 2003, p. 9-67.

OKE, T. R. Review of urban climatology: 1963-1973. Thecnical Note, 1974 v.134.

PREFEITURA MUNICIPAL DE VITÓRIA - PMV. Lei N 6.077 "Lei de Bairros de Vitória". Disponível em: http://sistemas.vitoria.es.gov.br/webleis/ Arquivos/2 003/L60 77.PDF. Acesso em 06 de maio de 2013.

Vitória. Disponível em: http://geoweb.vitoria.es.gov.br/. Acessado em 06/05/2013

REIBOTA, M. S.; GAN, M.A.; ROCHA, R.P.; AMBRIZZI, T. Regimes de precipitação na América do Sul: uma revisão bibliográfica. Revista Brasileira de Meteorologia. vol.25 n.2 São Paulo, 2010, p. 185 -204.

SANT'ANNA NETO, J.L.; AMORIM, M.C.C.T. O. Clima e segregação sócio espacial em cidades tropicais de porte médio. In: ENCUENTRO DE GEÓGRAFOS DE AMÉRICA LATINA, 12. 2009.Montevideo. Disponível em: http://egal2009.easyplanners.info/area07/7376_undefined__undefined.pdf. Acesso em: 01 de agosto de 2013.

WU, T., LI, Y. Spatial interpolation of temperature in the United States using residual kriging. Applied Geography,n. 44, p. 112 -120, 2013. 
CONTRIBUIÇÃO À COMPREENSÃO DO CAMPO TÉRMICO DA REGIONAL PRAIA DO CANTO, EM VITÓRIA (ES) PELA METODOLOGIA DE TRANSECTOS

YOSHINO, M.M. Development of urban Climatology and problems today. Energy and Building, 15-16, (1990-1991). p.1-10. 